\title{
Exploring the Differences in Drinking Motives among \\ Adolescent Binge and Non-Binge Drinkers
}

\author{
BY \\ CATHERINE M. YORK \\ B.A., University of Illinois at Chicago, 2005 \\ M.A., University of Illinois at Chicago, 2007
}

\section{THESIS}

Submitted as partial fulfillment of the requirements for the degree of Doctor of Philosophy in Psychology in the Graduate College of the University of Illinois at Chicago, 2013

Chicago, Illinois

Defense Committee:

Robin Mermelstein, Chair and Advisor Larry Grimm

Jon Kassel

Audrey Ruderman

Colleen Corte, College of Nursing 
This thesis is dedicated to my mother, my husband, Nick, and my daughter, Annabeth, for giving me the guidance, support, and motivation to pursue my dreams. 


\section{ACKNOWLEDGMENTS}

I would like to thank my advisor, Robin Mermelstein, for giving me such wonderful encouragement and guidance, as well as great amounts of her time, all of which I consider very valuable. I would also like to thank my thesis committee, Jon Kassel, Larry Grimm, Audrey Ruderman, and Colleen Corte for their support, assistance, and valuable feedback on this document. Without the vast amounts of knowledge and expertise that my committee gave, I would not have been able to achieve this accomplishment.

I would also like to thank two individuals who gave me amazing guidance and assisted me in the conceptualization, data management, and analytical processes of this study - Jennifer Veilleux and Drew Sturgeon. I greatly appreciated all of their support throughout this process, especially when I needed an objective viewpoint. 


\section{TABLE OF CONTENTS}

I. INTRODUCTION

A. Background and Purpose of the Study................................ 1

B. Definition of Binge Drinking ....................................... 2

C. Prevalence and Consequences of Binge Drinking among Adolescents...... 3

D. Theories Associated with Binge Drinking............................... 6

E. What are Drinking Motives.......................................... 7

1. Coping Motives............................................. 7

2. Enhancement Motives..................................... 8

3. Social Motives............................................... 9

F. Motivational Models of Alcohol Use.................................... 10

G. Hypothesized Risk Factors for Binge Drinking ........................ 11

1. Peers.................................................... 12

a. Peer Network...................................... 12

b. $\quad$ Peer Support......................................... 13

2. Negative Affect........................................... 15

a. Depression......................................... 16

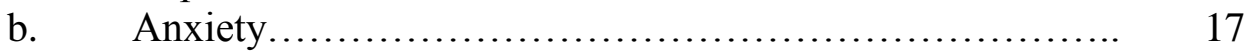

3. Temperament............................................ 18

H. Gender Differences.............................................. 19

I. The Current Study..................................................... 20

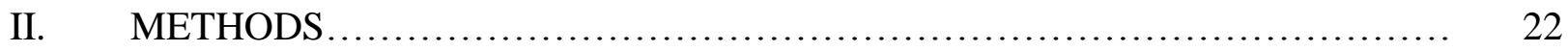
A. Overview of Design............................................... 22
B. Participants....................................................... 22
C. Procedures......................................................... 23
D. Measures.......................................................... 23

III. $\quad$ RESULTS ........................................................... 28

A. Preliminary Analyses............................................... 28

B. Overview of Data Analyses........................................ 29

1. Path Analyses............................................. 29

2. Model Specification........................................ 30

3. Evaluation of Model Fit.................................... 30

C. Cross-Sectional Path-Analytic Models.................................. 30

1. Females................................................... 31

2. Males..................................................... 32

D. Longitudinal Path-Analytic Models.................................. 33

1. Females.................................................... 33

2. Males...................................................... 34

E. Exploratory Cross-Sectional Moderated-Mediation Analyses.............. 35

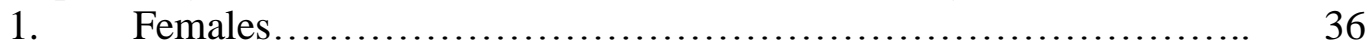

2. Males....................................................... 37 


\section{TABLE OF CONTENTS (continued)}

CHAPTER $\quad \underline{\text { PAGE }}$

F. Exploratory Longitudinal Moderated-Mediation Analyses.................. 38

1. Females................................................. 38

2. Males.................................................. 39

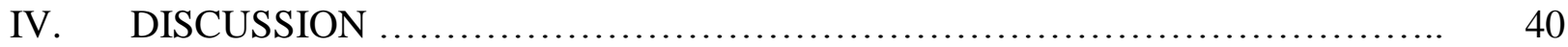

A. The Hypothesized Model........................................ 40

B. Motivational Differences between Binge and Non-Binge Drinkers......... 41

1. Negative Affect.......................................... 41

2. Temperament............................................. 43

3. Peers.................................................... 45

4. Previous Alcohol-Related Problems.............................. 47

C. Strengths and Limitations.......................................... 47

D. Conclusions and Future Directions................................. 49

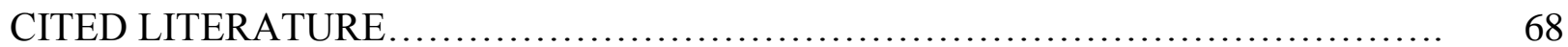

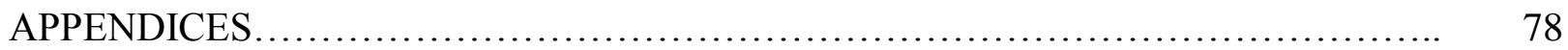

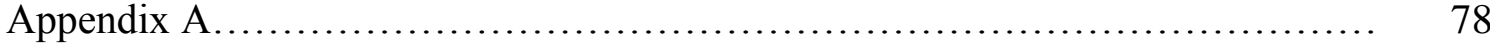

Appendix B........................................................... 79

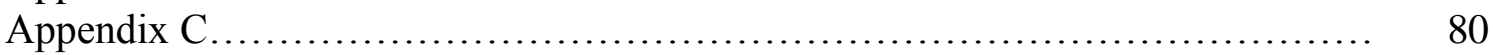

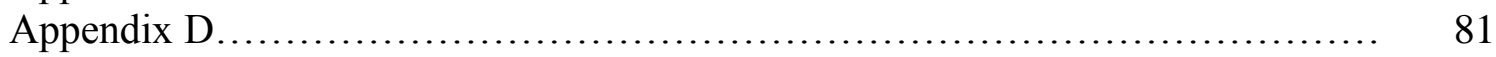

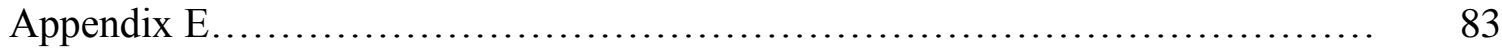

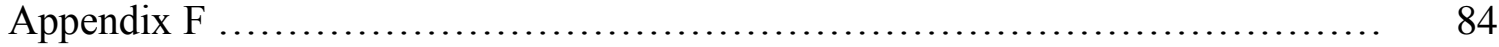

Appendix G ............................................................. 86

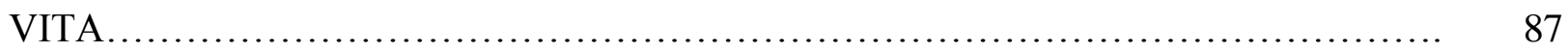




\section{LIST OF TABLES}

$\underline{\text { TABLE }}$

$\underline{\text { PAGE }}$

I. TIMELINE OF MEASURES/VARIABLES USED $\ldots \ldots \ldots \ldots \ldots \ldots \ldots \ldots \ldots \ldots . \ldots \ldots$

II. DEMOGRAPHIC AND BINGE STATUS OF THE SAMPLE, $N=772 \ldots \ldots \ldots \ldots \quad 53$

III. ALCOHOL USE CHARACTERISTICS OF THE SAMPLE, $N=772 \ldots \ldots \ldots \ldots \ldots \quad 54$

IV. MEANS AND STANDARD DEVIATIONS OF MAIN VARIABLES FOR THE TOTAL SAMPLE BY GENDER AND DRINKING STATUS ............. 55

V. CORRELATIONS BETWEEN ALL VARIABLES FOR 24-MONTH

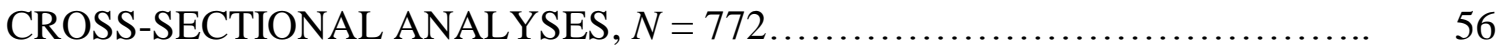

VI. CORRELATIONS BETWEEN ALL VARIABLES FOR 24-MONTH CROSS-SECTIONAL ANALYSES BY DRINKING STATUS, $N=772 \ldots \ldots \ldots \ldots . \quad 57$

VII. CROSS-SECTIONAL MODEL FIT INDICES $\ldots \ldots \ldots \ldots \ldots \ldots \ldots \ldots \ldots \ldots \ldots \ldots . \quad 58$

VIII. LONGITUDINAL MODEL FIT INDICES $\ldots \ldots \ldots \ldots \ldots \ldots \ldots \ldots \ldots \ldots \ldots \ldots \ldots \ldots \ldots \ldots \ldots$ 


\section{LIST OF FIGURES}

FIGURE $\underline{\text { PAGE }}$

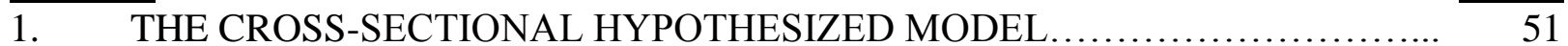

2. CROSS-SECTIONAL REVISED MODEL FOR FEMALES $\ldots \ldots \ldots \ldots \ldots \ldots \ldots \ldots$

3. CROSS-SECTIONAL REVISED MODEL FOR MALES $\ldots \ldots \ldots \ldots \ldots \ldots \ldots \ldots \ldots . \ldots$

4. LONGITUDINAL REVISED MODEL FOR FEMALES ..................... 62

5. LONGITUDINAL REVISED MODEL FOR MALES $\ldots \ldots \ldots \ldots \ldots \ldots \ldots \ldots \ldots \ldots . \ldots \ldots$

6. FEMALE CROSS-SECTIONAL MEDIATED-MODERATED ANAYLES

SEPARATED BY DRINKING MOTIVES................................ 64

7. MALE CROSS-SECTIONAL MEDIATED-MODERATED ANAYLES

SEPARATED BY DRINKING MOTIVES .................................... 65

8. FEMALE LONGITUDINAL MEDIATED-MODERATED ANAYLES

SEPARATED BY DRINKING MOTIVES.................................. 66

9. MALE LONGITUDINAL MEDIATED-MODERATED ANAYLES

SEPARATED BY DRINKING MOTIVES ............................... 67 


\section{LIST OF ABBREVIATIONS}

\begin{tabular}{|c|c|}
\hline ADIS & Adolescent Alcohol- and Drug-Related Problem Scale \\
\hline CES-D & Center for Epidemiological Studies - Depression Inventory \\
\hline $\mathrm{CFI}$ & Comparative Fit Index \\
\hline CMIN & Value of the Chi-Square \\
\hline$\chi^{2}$ & Chi-square \\
\hline$d f$ & Degrees of Freedom \\
\hline FS & Friend Support \\
\hline GFI & Goodness-of-Fit Index \\
\hline$M$ & Mean \\
\hline MASQ & Mood and Anxiety Symptom Questionnaire \\
\hline$N$ & Number in total group \\
\hline NS & Novelty Seeking \\
\hline$p$ & Probability \\
\hline$r$ & Pearson Product-Moment Correlations \\
\hline$R^{2}$ & Multiple Correlation Squared \\
\hline RMSEA & Root Mean Square Error of Approximation \\
\hline$S D$ & Standard Deviation \\
\hline SNITS & Social Network Inventory for Tobacco Smokers \\
\hline
\end{tabular}




\section{SUMMARY}

Alcohol use often escalates during the period of middle to late adolescence (ages 16 to 20; Brown et al., 2008), which can lead to binge drinking (defined as five or more drinks for males and four or more drinks for females during one drinking occasion). Binge drinking is one of the leading public health concerns for adolescents and may lead to several alcohol-related problems (Courtney \& Polich, 2009). The primary goal of this study was to expand upon a motivational model of alcohol use (Cooper, Frone, Russell, \& Mudar, 1995) to better understand how binge and non-binge drinkers may differ in their drinking motives, or reasons for drinking.

This model was tested cross-sectionally and longitudinally using a sample of adolescents who may be considered at high risk for problem behaviors. Participants were $77211^{\text {th }}$ and $12^{\text {th }}$ graders (59\% female; $79 \%$ white) in a longitudinal study of the social and emotional contexts of adolescent smoking patterns; 430 of whom (55\% female) met criteria as binge drinkers. Two sets of nested structural models were tested using path analysis for four groups created based upon gender and binge status (female binge drinkers, female non-binge drinkers, male binge drinkers, and male non-binge drinkers) and included five exogenous variables (depression, anxiety, novelty seeking, friend support, and problem-behavior network) and four endogenous variables (coping, enhancement, and social motives and alcohol-related problems). The first set examined cross-sectional, structural relations among model variables, and the second set examined the same variables longitudinally in which 15 -month exogenous variables were entered predicting 24-month drinking motives and alcohol-related problems. Two models were tested for each group: one positing full mediation by drinking motives (i.e., the hypothesized cross-sectional/ longitudinal model) and the other allowing for estimation of direct paths suggested by AMOS modification indices to improve overall model fit. Multi-group analyses were conducted to 


\section{SUMMARY (continued)}

determine significant differences between binge and non-binge drinkers for each gender. Finally, a series of moderated-mediation analyses were conducted to examine each drinking motive separately using bootstrap mediation techniques and multi-group analyses in AMOS to better explore significant differences in drinking motives between binge and non-binge drinkers.

Overall, the current study found that depression, anxiety, novelty seeking, and socializing with a problem-behavior network was associated with alcohol-related problems both directly and indirectly via drinking motives, with some antecedents (i.e., anxiety, novelty seeking, and problem-behavior network) being associated with more than one drinking motive. There were also significant differences between binge and non-binge drinkers, as well as between males and females. Specifically, depression was indirectly related to alcohol-related problems via coping motives for non-binge drinkers, whereas anxiety was indirectly related to alcohol-related problems via coping motives for binge drinkers. In addition, the relationship between associating with a problem-behavior network and alcohol-related problems was mediated by social motives for all females but only for binge-drinking males. Finally, the meditational role of enhancement motives between novelty seeking and alcohol-related problems was found for all groups, regardless of binge status and gender. These results suggest that future interventions for adolescent drinking should be sure to incorporate strategies based upon each drinking motivation. 


\section{INTRODUCTION}

\section{A. Background and Purpose of the Study}

Adolescence is the developmental period in which individuals are at the most risk for initiating alcohol use (Chassin \& DeLucia, 1996; Schulenberg, Maggs, Steinman, \& Zucker, 2001). Alcohol use often escalates during the period of middle to late adolescence (ages 16 to 20;

Brown et al., 2008), which may lead to binge drinking (usually defined as five or more drinks for males and four or more drinks for females during one drinking occasion). While some drinking behaviors during this developmental period may be normative, binge drinking is one of the leading public health concerns for adolescents (Courtney \& Polich, 2009; Johnston, O'Malley, Bachman, \& Schulenberg, 2012) and may lead to health, academic, and social problems (e.g., lower educational aspirations, delinquency, increased drug and tobacco use, and higher levels of depression) that can interfere with successful adult development (Masten, Faden, Zucker, \& Spear, 2008).

Previous research has identified several variables that serve as risk factors for binge drinking among adolescents, including social influence, affective states, personality factors, and drinking expectancies (Chassin, Pitts \& Prost, 2002; Courtney \& Polich, 2009; Tucker, Orlando, \& Ellickson, 2003). Drinking motives, or one's reasons for drinking, are also predictive of both binge drinking and alcohol-related problems among adolescents (Cooper, 1994; Schulenberg, Wadsworth, O’Malley, Bachman, \& Johnston, 1996). Furthermore, while theoretical models of binge drinking have been proposed and tested (Durkin, Wolfe, \& Clark, 1999; Gibson, Schreck, \& Miller, 2004; Johnson \& White, 2003; Norman, Bennett, and Lewis, 1998; Oei \& Morawska, 2004), none of them has attempted to incorporate drinking motives to help explain why an adolescent partakes in binge drinking. 
Cooper, Frone, Russell, and Mudar (1995) constructed and tested a motivational model of alcohol use among a sample of adolescents. They found that expectancies, emotions, and personality traits were associated with coping and enhancement motives for alcohol use, and in turn, that these motives led not only to alcohol use, but to alcohol-related problems as well (Cooper et al., 1995). While research has built upon this work (Read, Wood, Kahler, Maddock, \& Palfai, 2003), it is unknown how drinking motives may differ between those adolescents who binge drink and those who do not. In addition, it is unknown whether these relationships differ between males and females. The primary goal of this study is to understand better how binge and non-binge drinkers may differ in their drinking motives and potential paths to alcohol-related problems using a sample of adolescents who may be considered at high risk for problem behaviors. Understanding how motives may differ between binge and non-binge drinkers can aid in determining if there should be different prevention and intervention programs specifically designed for these two different groups.

This paper will first provide an overview of the definition, prevalence, and consequences of adolescent binge drinking. The focus will then shift to theories of binge drinking, a description of a motivational model of alcohol use (briefly described above) that may apply to binge drinking, followed by specific antecedent factors that are likely predictive of binge drinking via drinking motives. Finally, the current study and research questions will be discussed.

\section{B. Definition of Binge Drinking}

Currently, binge drinking is defined by the quantity used on a given occasion (Courtney \& Polich, 2009). The National Institute on Alcohol Abuse and Alcoholism (NIAAA; 2004) proposed a standardized definition for binge episodes, stating that a "binge" involves consuming five or more drinks for males or four or more drinks for females (which raises the blood alcohol 
level to .08 , on average) within a two hour period. Although this definition describes a single binge, binge drinking is a patterned behavior of repeated binge episodes.

Typically, individuals may be classified as "binge drinkers" if they engage in a binge episode at least once in the two weeks prior to the assessment point (Oei \& Morawska, 2003). However, other researchers suggest a longer time frame may be more appropriate. For example, Vik, Tate, and Carrello (2000) used a two week and three month time frame with a sample of college students and found that almost a third of students were classified as non-bingers using the two week timeframe but were categorized as binge drinkers using the extended timeframe. This difference may be due to variability in drinking opportunities or occasions that may keep students from engaging in alcohol use, such as class assignments or exams. The authors concluded that three months is long enough to correctly characterize drinkers, but short enough that it would not affect the student's recall of drinking episodes (Vik et al., 2000). Thus, the best

time frame should be long enough to capture a valid estimate of binge drinking, while optimizing the accuracy of self-reported drinking amounts and capturing the problems associated with this drinking pattern (Courtney \& Polich, 2009).

\section{Prevalence and Consequences of Binge Drinking among Adolescents}

Adolescents drink less often when compared to adults; however, they tend to drink more per occasion (Masten et al., 2008). Perhaps this is because, due to the illegality of alcohol for underage individuals, drinking is opportunistic. Thus, many adolescents may feel a necessity to consume large amounts of the alcohol they were able to obtain. This "necessity" to drink large amounts of alcohol may lead some adolescents to binge drink, and drinking with the intention "to get drunk" has been shown to be a risk factor for binge drinking (Schulenburg et al., 1996). 
While binge drinking rates among high school students have remained stable over the past decade, binge drinking still remains a significant problem (Johnston et al., 2013). Data from the Monitoring the Future survey (Johnston et al., 2013) indicated that $5 \%$ of $8^{\text {th }}$ graders, $16 \%$ of $10^{\text {th }}$ graders, and $24 \%$ of $12^{\text {th }}$ graders reported binge drinking during the two weeks before the survey.

By the 12th grade, there are differences in binge drinking between males and females (Windle, 2003); the modal adolescent binge drinker is white and male (Johnston et al., 2013). Whereas lifetime prevalence of alcohol use for males and females in the 12th grade is about the same (about $69 \%$ for both; Johnston et al., 2013), males report higher rates of binge drinking than females during this time period (27\% versus $20 \%$, respectively; Johnston et al., 2013). While this difference is found throughout high school, it becomes much more pronounced in the upper grades (i.e., among $12^{\text {th }}$ graders; Johnston et al., 2013). Schulenburg and colleagues (1996) found being male predicted future binge drinking regardless of how much and how often one binge drank during their senior year of high school.

Given the prevalence of the problem on many college campuses (Wechsler, Davenport, Dowdall, Moeykens, \& Castillo, 1994) most of the research on binge drinking focuses on college students. However, drinking patterns, such as frequent binge drinking, are usually established during high school (Ham \& Hope, 2003) and do not considerably change as adolescents move from high school to college (Hildebrand, Johnson, \& Bogle, 2001). For example, many studies have found that engaging in binge drinking during high school is predictive of binge drinking in college and young adulthood (McCarty, Ebel, Garrison, DiGiuseppe, Christakis, \& Rivara, 2004; Wechsler, Dowdall, Davenport, \& Castillo, 1995; Weitzman, Nelson, \& Wechsler, 2003). 
An adolescent's drinking behaviors may have deleterious effects during their college years, and subsequently, their adulthood (McCabe, 2002). Alcohol involvement, especially binge drinking, may lead to short- and long-term harmful consequences, which are often termed "alcohol-related problems". According to Brown et al. (2008), alcohol-related problems can refer to a variety of negative life events, including "social problems (e.g., physical or verbal aggression or relationship difficulties), legal problems (e.g., arrests for driving while intoxicated [DWI] or public inebriation), educational/vocational problems (e.g., academic difficulties, termination from employment, or failure to achieve career goals), and medical problems (e.g., unintentional injury, liver disease, or central nervous system disease)" (p.15). Alcohol-related problems resulting from binge drinking also include neurological problems, such as deficits in frontal lobe functioning, working memory, neural systems, and long-term memory (Courtney \& Polich, 2009). Research has found a strong, positive relationship between the frequency of binge drinking among college students and number of alcohol-related problems (Wechsler et al., 1994). Interestingly, while binge drinking has been linked to numerous negative consequences (Courtney \& Polich, 2009), only $49 \%$ of $12^{\text {th }}$ graders feel that there is a "great risk" associated with drinking at this level (Johnston et al., 2013) and many feel that it is a rite of passage into adulthood (Schulenburg et al., 1996).

When compared to other adolescents who do not drink or drink but do not binge, those who binge drink are much more likely to engage in other high risk behaviors (Miller, Naimi, Brewer, and Jones, 2007). Specifically, Miller et al. (2007) compared adolescents who did not drink, who drank but did not binge drink, and those who binge drank on a number of high risk behaviors. The authors found that compared to non-drinkers and current drinkers who did not binge drink, binge drinking adolescents were more likely to ride in a car with a driver who had 
been drinking, engage in risky sexual behaviors (e.g., no condom use or using alcohol or drugs before sexual intercourse), use tobacco or other drugs, and be involved in interpersonal violence (e.g., physical fight or dating violence).

Hill, White, Chung, Hawkins, and Catalano (2000) found that when compared to nonbinge drinkers, binge drinkers had the lowest prevalence of prosocial outcomes (e.g., involvement in clubs/activities, high school completion) and highest prevalence of antisocial outcomes (e.g., crime, substance abuse/dependence). Chassin and colleagues (2002) found that binge drinkers had the highest risk for negative short-term consequences (defined by number of antisocial personality symptoms), as well as developing alcohol and drug abuse or dependence in adulthood. Furthermore, drinking patterns among college students are correlated with alcohol diagnoses (Knight, Wechsler, Kuo, Seibring, Weitzman, \& Schuckit, 2000); such that students who were classified as "binge drinkers" had significantly greater odds of being classified with alcohol abuse or dependence.

\section{Theories Associated with Binge Drinking}

Researchers have found multiple factors that are associated with adolescent binge drinking, including social bonds and attitudes (Durkin et al., 1999; Johnson \& White, 2003), perceived behavioral control (Norman et al., 1998; Gibson et al., 2004), and alcohol expectancies (Morawska \& Oei, 2005). Multidimensional theories suggest that there are multiple factors that can account for adolescent binge drinking and that aspects of them seem to work in conjunction with each other. Cox and Klinger (1988) suggested that drinking motives are the "final common pathway" between distal risk factors (e.g., affect or stress) and alcohol use. Therefore, motivational models of binge drinking are useful in identifying not only the reasons why an individual chooses to engage in this behavior, but also the variables that lead one to make those 
decisions. According to Cooper (1994), drinking alcohol is motivated by different needs and is characterized by distinct relationships between antecedents and consequences. Therefore, by examining the motives behind adolescent binge drinking, we can better determine the circumstances in which adolescents may binge and what the likely outcomes, or consequences, of this behavior will be (Cooper, 1994).

\section{E. What are Drinking Motives?}

As stated earlier, Cox and Klinger (1988) proposed that the final common pathway to alcohol use is motivational, such that while there are several contributing factors that play a role in the etiology of alcohol problems, motivations for drinking alcohol are the "gateway in which more distal influences are mediated" (Cooper, 1994, p. 117). Three drinking motives will be examined in the current study: 1) coping, 2) enhancement, and 3) social (defined more below). Cooper, Russell, Skinner, and Windle (1992) used confirmatory factor analysis among a large sample of adults to show that each motive constitutes an empirically distinct factor. In addition, each drinking motive was examined for its differential associations with alcohol use and abuse. The authors found that each motive was associated with a unique pattern of alcohol use and alcohol-related consequences, which will be described below (Cooper et al., 1992). Furthermore, Cooper (1994) later replicated these results using a sample of adolescents and found that the patterns of alcohol use and alcohol-related consequences were remarkably similar to adults, suggesting that adolescent drinking motives may be an important predictor of alcohol use and problems in adulthood.

\section{Coping Motives}

Coping motives, or drinking to cope with negative affective states, is associated with alcohol-related problems and frequent drinking among adults and adolescents (Cooper et al., 
1992; Cooper, 1994; Kuntsche, Knibbe, Gmel, \& Engels, 2005; Windle \& Windle, 1996). When compared to those individuals who drink for social or enhancement reasons, those who drink for coping reasons are more likely to develop alcohol-related problems (Cooper, 1994).

Furthermore, alcohol use as a means of coping with negative affect has also been shown to be an important predictor of future binge drinking among adolescents (Pirkle \& Richter, 2006;

Schulenberg et al., 1996) and as a predictor of heavy drinking among college students (Rutledge \& Sher, 2001). The relationship between coping motives and alcohol-related problems may be due to deficiencies in one's general perceptions of one's ability to cope with negative affect; it has been shown that individuals who have deficiencies or perceptions of deficiencies in their coping ability are more likely to have alcohol problems (Kassel, Jackson, \& Unrod, 2000).

\section{Enhancement Motives}

Enhancement motives refer to the internal positive reinforcement that one receives from alcohol use. Specifically, these motives pertain to the use of alcohol to achieve positive affective states or to reap the physical benefits of alcohol (e.g., relaxation). Interestingly, when TerryMcElrath, O’Malley, and Johnston (2009) examined drinking motives using 30 years of crosssectional data gathered on high school seniors, they found that enhancement reasons were consistently the most often reported reasons for use (e.g., drinking "to get high", "to have a good time", and "to experiment", p.686) ${ }^{1}$.

Enhancement motives have been found to predict heavier, more frequent drinking and an increase in the frequency of drinking until drunk (Cooper et al., 1992; Cooper, 1994; Ham \& Hope, 2003). Compared to those individuals who drink for coping reasons, individuals who drink

\footnotetext{
${ }^{1}$ It is noted that Terry-McElrath et al. classify this self-reported reason for substance use as "social/recreational reasons"; however, the specific reasons mentioned above would be considered enhancement reasons via Cooper's (1992) three-dimensional measure of drinking motives.
} 
for enhancement reasons are more likely to drink more heavily but are less likely to report alcohol-related problems (Cooper et al., 1992; Cooper, 1994). This may be because individuals who drink to cope may acquire a dependence on alcohol to regulate their negative affect leading to less control over their alcohol use; however, those who drink for enhancement may have more control over when, where, and how much they drink (Cooper et al., 1992). While those adolescents who drink for enhancement purposes are less likely to report alcohol-related problems, Schulenberg et al. (1996) found that adolescents who drank to get drunk (similar to an enhancement motive) were at a significant risk for increased binge drinking over a period of five years. In addition, enhancement motives have been shown to predict binge drinking in college students (Collins, Koutsky, Morsheimer, \& MacLean, 2001).

\section{Social Motives}

Social motives refer to the external positive reinforcement that one receives from alcohol use, such as socializing with one's family or friends. It is important to note that social motives do not include the pressure to conform to drinking, or peer pressure. Instead, social motives refer to drinking alcohol for social reasons, such as to celebrate a social occasion or to partake in the behavior with friends (Cooper et al., 1992). Interestingly, whereas social motives are positively associated with quantity and frequency of use, there is mixed research about their association with alcohol-related problems. Some research has not found an association between social motives and alcohol-related problems (Cooper et al., 1992; Cooper, 1994); however, Bradizza, Reifman, \& Barnes (1999) found that social motives were predictive of alcohol misuse (defined by drinking two or more drinks per episode, at least once per week; one binge episode in the past year; and being drunk at least once in the past year) among older adolescents. They speculate that this may be because heavy social drinking can be normative among older adolescents; thus, 
more adolescents in this age group (ages 16 to 18) may be using larger quantities of alcohol frequently to meet their social needs (Bradizza et al., 1999).

\section{F. Motivational Models of Alcohol Use}

Cooper and colleagues (1995) developed and tested a motivational model of alcohol use focusing on the antecedents and consequences of drinking to enhance positive affect and to cope with negative affect. Specifically, they predicted that social/emotional enhancement expectancies and sensation seeking would lead to enhancement motives and that tension reduction expectances, negative emotion, and avoidance coping would lead to coping motives. They then predicted that these drinking motives would lead to alcohol use (defined by frequency, quantity, and binge drinking episodes), which would, in turn, lead to alcohol problems. Using a sample of adolescents (ages 13-19), the authors found that social/emotional enhancement expectancies and sensation seeking were positively associated with enhancement motives, and drinking to enhance was predictive of alcohol use. In addition, they found that tension reduction expectancies and negative emotion were positively associated with coping motives, and that coping motives predicted drinking problems over and above its indirect contribution via alcohol use. The authors stated that this study gives support for the notion that alcohol use and drinking problems should be examined through "multiple etiologic pathways" versus treating alcohol use as a unitary phenomenon (Cooper et al., 1995).

Read and colleagues (2003) expanded upon Cooper et al.’s (1995) motivational model by including social antecedents (alcohol offers from peers and one's perceived peer drinking environment) and by testing the model using a sample of college students. They found similar results to Cooper et al. (1995) in regards to coping and enhancement motives, and in addition, they found that alcohol offers and perceived peer drinking environment predicted social motives. 
Moreover, only enhancement motives were significantly predictive of alcohol use (defined by quantity and frequency), whereas coping motives were the only variable predictive of alcoholrelated consequences (defined as general [e.g., hangovers or blackouts] and college-specific [e.g., missing class] consequences). Finally, social motives were not predictive of either alcohol use or alcohol-related consequences. Overall, the authors concluded that their results were consistent with those of Cooper et al. (1995), and furthermore, that alcohol use was strongly related to one's social environment (Read et al., 2003).

In the same manner as Cooper and colleagues (1995), the current study conceptualizes alcohol use as a motivated behavior, and the motives represented "are depicted as the proximal determinants of consumption, providing a final common pathway though which more distal influences are mediated" (p. 991). The current study will build upon Cooper et al.'s (1995) previous work by 1) including social influences and motives (similar to Read et al., 2003); 2) utilizing a group of high-risk adolescents; 3) comparing the models for binge and non-binge drinkers; 4) comparing the relationships between males and females; and 5) testing hypotheses longitudinally to determine the prospective relationships between psychosocial factors and drinking motives, binge drinking, and alcohol-related problems.

\section{G. Hypothesized Risk Factors for Binge Drinking}

As stated earlier, the overall goal of the current study is to better understand pathways leading to binge drinking. Many risk factors for engaging in binge drinking have been identified; these include exposure to a "prodrug" social environment, deviant behavior, other drug use, and low self-efficacy (Schulenburg et al., 1996; Tucker et al., 2003). The current study will focus specifically on three types of antecedent factors that serve as risk factors for binge drinking, hypothesized to operate via drinking motives. These are: 1) peers (e.g., network and support), 2) 
negative affect (e.g., depression and anxiety), and 3) temperament (e.g., sensation seeking).

While all of these factors have been shown to separately influence adolescent alcohol use, together they may be a particular catalyst specifically for binge drinking.

\section{1. $\quad \underline{\text { Peers }}$}

According to the peer cluster theory (Oetting \& Beauvais, 1987), socialization characteristics are a highly predictive variable of adolescent alcohol use, and among all socialization measures (e.g., family, school, and religion) associating with peers who use alcohol/drugs is the dominant predictor of adolescent alcohol use. Furthermore, social environment has been shown to serve as a critical risk factor for binge drinking among college students because these students frequently choose to associate with a peer environment that facilitates this behavior (Courtney \& Polich, 2009). Considerable research has shown that peer network and peer support are related to both alcohol use and binge drinking (Tucker et al., 2003; Wills, Resko, Ainette, \& Mendoza, 2004).

\section{a. $\quad$ Peer Network}

Adolescents who associate with peers who binge drink are at a much higher risk of partaking in binge drinking (Chassin \& DeLucia, 1996; Curran, Stice, \& Chassin, 1997; Tucker et al., 2003; Wills \& Cleary, 1996). One's peer network has been shown to predict binge drinking through direct (e.g., alcohol offers) and indirect (e.g., modeling) ways (Borsari \& Carey, 2001). Using a sample of Swedish adolescents, Svensson (2010) found that those students who attended schools with high amounts of binge drinking were more likely to engage in that behavior. In addition, associating with deviant peers has been identified as a risk factor for binge drinking among adolescents (Tucker et al., 2003). 
In a review of peer influence on college drinking, Borsari and Carey (2001) stated that a consistent finding among college students is that their alcohol-related attitudes and behaviors are greatly influenced by those of their peers, especially in regards to binge drinking. For example, Jamison and Myers (2008) found that friends' drinking behavior (quantity per episode and frequency) was predictive of binge drinking among college students. Interestingly, binge drinkers tended to match their friends on quantity and frequency of use, but were not directly encouraged or expected to do so by their peers. They concluded that contrary to the notion that all drinking behaviors are related to peer pressure or a need to conform, binge drinking may be related to more social factors, such as acceptance or approval (Jamison \& Myers, 2008). This is consistent with the findings of Norman et al. (1998) who found that perception of the social pressure to engage in binge drinking was not predictive of binging.

Stice, Barrera, \& Chassin (1998) found that peer influence promoted problem alcohol use (defined by the number of social, health, academic and legal consequences resulting from alcohol use) among adolescents directly and indirectly via alcohol consumption. Specifically, while peer influence was predictive of alcohol use, the authors also found that alcohol consumption (defined by quantity and frequency) mediated this relationship (Stice et al., 1998). Thus, the amount and frequency of which an adolescent drank mediated the relationship between peer influence and problem alcohol use. The current study will take this finding further by determining if social motives mediate the relationship between one's peer network and binge drinking, as well as between peer network and alcohol-related problems.

\section{b. $\quad$ Peer Support}

Wills \& Cleary (1996) have defined social support as a resource that helps one cope with stressful life events by increasing one's abilities to regulate emotions and problem solve. There 
are many different domains from which an individual receives social support, and for adolescents one main domain of interest includes peers, as the support received from peers becomes more emotionally rewarding in adolescence because it brings a sense of belonging and companionship (Larson \& Richards, 1991). Thus, increased autonomy, decreased parental supervision, and greater involvement with peers all combine to produce the opportunity for adolescents to partake in binge drinking, and in turn, experience alcohol-related problems (Brown et al., 2008).

Research has found that peer support, defined as how much an adolescent turns to a close friend for help, is positively related to alcohol use (Wills \& Vaughn, 1989; Wills et al., 2004). This finding may be due to a combination of factors, including social activities and peer attitudes towards drinking. Adolescents who perceive peers as more supportive will likely spend more time in peer-group activities (Wills \& Vaughn, 1989), and as Wills and colleagues (2004) stated, these activities are often have a "positive hedonic tone" (p. 123) and are often focused on spontaneous and impulsive behavior. Thus, taking part in peer activities will likely expose adolescents to more situations that involve alcohol use (Wills \& Vaughn, 1989). In addition, compared to parents, an adolescent's peers may have a more favorable attitude towards alcohol use, with this behavior being encouraged, or at least not discouraged among an adolescent's peer network (Wills et al., 2004), which may lead an adolescent to misinterpret the support from their peers as support to engage in alcohol use.

While Durkin et al. (1999) theorized that binge drinking occurs when one's social bond is weak or lacking, Johnson \& White (2003) found that college students who perceived normative support for drinking from their peers were more likely to have intentions to binge drink. In addition, results indicated that attitudes and subjective norms of binge drinking among one's peer network also influenced this behavior. More specifically, consistent with the findings of Wills et 
al. (2004), college students whose peers had positive attitudes towards binge drinking and who perceived that their peers were taking part in this behavior were more likely to engage in binge drinking. Thus, as peer support has been shown to be predictive of alcohol use among adolescents (Wills et al., 2004) and of binge drinking among college students (Johnson \& White, 2003), it is likely that it also serves a risk factor for binge drinking for adolescents.

In sum, when examining the pathway to binge drinking among adolescents, it is important to include the support that they receive from their peers and the extent to which their peer network is engaging in problematic behaviors, including alcohol use. The current study will include both a measure of peer support (Will's Social Support Scale; Wills et al., 2004) and the amount of peers engaging in problematic behaviors, including alcohol use (Social Network Inventory for Tobacco Smokers; Mermelstein, Cohen, Lichtenstein, Baer, \& Kamarck, 1986) to represent the "social" antecedents of adolescent drinking.

\section{2. $\quad$ Negative Affect}

According to Rosenberg (1998), there are two types of affect: traits and states. While affective traits refer to a part of one's personality and remain stable over time, states are temporary and influenced by one's environment (Rosenberg, 1998). The current study will examine negative affective states, which are often measured by using affective symptom clusters of depression and/or anxiety (Hussong \& Chassin, 1994).

The construct of negative affect and its relation to alcohol use has been examined often within the substance use literature (e.g. Cooney, Litt, Morse, Bauer, \& Gaupp, 1997; Hussong, Hicks, Levy, \& Curran, 2001; Wills, DuHamel, \& Vaccaro, 1995; Wills \& Shiffman, 1985), and some researchers have posited that the desire to regulate negative affect is the primary motive for substance use (Baker, Piper, McCarthy, Majeskie, \& Fiore, 2004). There is also considerable 
empirical support linking negative affect to alcohol use among adolescents (e.g., Wills, McNamara, Vaccaro, \& Hirky, 1996; Wills, Sandy, Shinar, \& Yaeger, 1999; Wills, Sandy, Yaeger, Cleary, \& Shinar, 2001; Windle \& Windle, 1996). In addition, it has been suggested that negative affect is a stronger predictor of problematic alcohol use than "normative" use among adolescents (Chassin et al., 2002). Thus, adolescents with high levels of negative affect may be at an increased risk for binge drinking.

The stress-coping model (Wills \& Shiffman, 1985) posits that alcohol use among individuals, including adolescents, may serve as a means of emotional self-regulation. This theory emphasizes three main points: 1) adolescents have less adequate coping skills than most adults, and as such, may be at higher risk of engaging in substance use to regulate their negative affect; 2) negative affect may be a reason behind experimental substance use and, in turn, the alleviation of negative affect may become the reason for prolonged and heavy use; and 3) if adolescents expect a substance, such as alcohol, to alleviate their negative affect, they will be more likely to engage in their behavior, which can lead to heavy substance use (Kassel, Weinstein, Skitch, Veilleux, \& Mermelstein, 2005).

\section{a. Depression}

There has been much research showing a relationship between depression and substance use disorders in adolescents. In fact, some studies have shown cormorbidity rates as high as $73 \%$. Whereas the temporal relationship between the onset of depressive symptoms and substance use disorders is still under examination, it is likely that depressive symptoms are a risk factor for both substance use and substance use disorders (Deas \& Thomas, 2002). For example, Kaplow, Curran, Angold, \& Costello (2001) found that children who reported higher rates of depression were significantly more likely to report engaging in alcohol use in adolescence. Adolescents who 
use alcohol are also commonly characterized as depressed (Deykin, Levy, \& Wells, 1987), and high levels of substance use have been shown to be strongly related to negative affect (Wills et al., 1999). Furthermore, depression has been found to be a strong predictor of binge drinking among adults (Bonin, McCreary, \& Sadava, 2000; Grzywacz \& Almeida, 2008), and Chassin et al. (2002) found that depression was a risk factor for binge drinking among adolescents, particularly among females.

\section{b. $\quad$ Anxiety}

Anxiety and alcohol use disorders are highly comorbid, such that those with an anxiety disorder have a 50-70\% increase in the odds of being diagnosed with an alcohol use disorder (Kushner, Abrams, \& Borchardt, 2000). Kaplow et al. (2001) found that children who had higher amounts of generalized anxiety symptoms were more likely to initiate alcohol use in adolescence. In addition, anxiety may be related with drinking to cope among adolescents and young adults, which researches feel is due to its anxiolytic properties (Kuntsche, Knibbe, Gmel, \& Engels, 2006). Anxiety may also have a unique relationship with drinking socially for adolescents, such that since they often engage in alcohol use to "fit in" with their peers, it is possible that once they are in these social situations, they may use alcohol to also alleviate their generalized anxiety symptoms, such as worry and tension (Kaplow et al., 2001).

While these constructs of negative affect are highly correlated, Hussong and Chassin (1994) warn against using a variety of affective states to create a single measure of negative affect because research has shown that different affective states (i.e., depression or anxiety) have unique relationships with alcohol use (Hussong \& Chassin, 1994; Kaplow et al., 2001). Testing the differential mediating effects of depression, anxiety, and anger on the relationship between stress and alcohol use among adolescents, Husson and Chassin (1994) found that only depression 
had a unique effect on this relationship. Furthermore, Kaplow et al. (2001) found differential effects for two types of anxiety (generalized and separation) on later alcohol use among adolescents, such that while generalized anxiety predicted later alcohol use, separation anxiety was associated with decreased risk of later alcohol use among adolescents. Hussong and Chassin (1994) concluded that their findings "suggest that alcohol use may be one behavioral arena of importance in testing the distinction among different forms of negative affect" (p. 714). Therefore, the current study will examine the differential effects of depression and anxiety on binge drinking, which will be relatively unique to this research, as they have not been examined simultaneously within the context of adolescent binge drinking.

\section{Temperament}

Temperament, or characteristics that appear early in one's life and are consistent and stable over time and situations (Zuckerman, Kuhlman, Joireman, Teta, \& Kraft, 1993), is another factor that has been studied in relation to alcohol use. Impulsivity, defined as a lack of planning and to act without thinking (Zuckerman et al., 1993), has been shown to be related to the construct of novelty seeking, or "frequent exploratory activity and exhilaration in response to novel or appetitive stimuli” (Wills, Vaccaro, \& McNamara, 1994, p. 1). Furthermore, impulsivity and novelty seeking have been found to be related to adolescent alcohol use, such that adolescents who are highly impulsive are at a much greater likelihood of engaging in alcohol related behaviors (Chassin \& DeLucia, 1996; Colder \& Chassin, 1999), and adolescents who score higher on novelty seeking have higher amounts of alcohol use (Wills et al., 1994).

Adolescents who score higher on novelty seeking may be more likely to engage in alcohol use because there may be an increased motivation to obtain stimulation from this behavior, greater responsivity to alcohol's effects, and a greater likelihood of engaging in this 
behavior without considering the consequences (Read et al., 2003). Thus, novelty seeking is an important predictor of enhancement drinking, as it is conceptually viewed as an appetitive behavior (Cooper et al., 1995). The current study will expand upon previous literature by seeking to determine differences in the relationships of novelty seeking, enhancement motives, and alcohol-related problems among binge and non-binge drinkers.

\section{H. Gender Differences}

Research has shown that there are many differences between males and females not only in regards to binge drinking (as described previously) but also in regards to negative affect, peer influence, and drinking motives. For example, Norman et al. (1998) found that males not only engaged in binge drinking more frequently than females, but also held more positive attitudes towards the behavior, felt like they were under more social pressure to binge drink, and noted more events that would increase the likelihood of binge drinking (e.g., celebrations). Moreover, Liu and Kaplan (1996) found that females tended to binge drink when they felt angry or worthless and when they wanted to get away from their problems. Conversely, males tended to engage in binge drinking to gain peer approval or to show that they were not afraid. Furthermore, some research has shown that adolescent and young adult males are more influenced to binge drink by their peers than females (Jamison \& Myers, 2008; Treiman \& Beck, 1996), whereas others have found that females are more influenced by their peers (Svensson, 2010).

In a review of 82 studies, Kuntsche and colleagues (2006) found that females tended to score higher on coping motives during early adolescence (ages 13 to 15); however, by late adolescence (ages 18 to 19), males tended to score higher on all three drinking motives (Kuntsche et al., 2006). Additional research has found similar results, such that males' strength of endorsement of social and enhancement motives tend to be higher than females (Cooper, 
1994; Terry-McElrath et al., 2009), whereas females more often report coping with negative affect than males (Terry-McElrath et al., 2009). The current study with examine the differences in motivational pathways to alcohol-related problems between binge and non-binge drinking adolescents separately for males and females due to the well-documented variations in alcoholuse and drinking motives between the genders.

\section{The Current Study}

The current study will examine the differences in a motivational pathway to alcohol problems between binge and non-binge drinkers using a high-risk sample of adolescents. This sample should make the pathways to alcohol problems more evident because of the higher prevalence of problem behaviors (Chassin et al., 2002; Johnson, Boles, Vaughan, \& Kleber, 2000). While Cooper et al.'s (1995) work demonstrated that alcohol use among adolescents may be differentially explained through consideration of different motivational pathways, little is known about how peer factors, temperament, and negative affect together may lead to certain motivations, how those motivations may differ between binge and non-binge drinkers, and how these relationships may differ between males and females.

The hypothesized model (see Figure 1) posits that depressive and anxiety symptoms will be associated with coping motives, that novelty seeking will be related to enhancement motives, and that peer support and belonging to a problem behavior network will predict social motives. It is also hypothesized that these antecedents will be specifically associated with each drinking motive (i.e., they will not be related to other drinking motives than the ones described above). Furthermore, it is predicted that these motives will lead to alcohol-related problems. While it is hypothesized that this model will significantly differ between binge and non-binge drinking adolescents and between males and females, the three specific questions that will be addressed 
by this study are: 1) How does the hypothesized model differ between binge and non-binge drinking adolescents?; 2) How does the hypothesized model differ between males and females?; and 3) Which of the hypothesized antecedents will significantly predict later motivations for drinking? 


\section{METHODS}

\section{A. Overview of Design}

The data for this study come from a longitudinal study of the social and emotional contexts of adolescent smoking patterns. A multi-method approach was utilized in this longitudinal study to assess adolescents at five time points: baseline, 6-, 15-, 24-, and 33-months. The data collection modalities included week-long time/event EMA sampling, paper-and-pencil self-report questionnaires, and in-depth interviews. Data for the current study included 15- and 24-month self-report questionnaire measures.

\section{B. Participants}

Participants for this study were initially recruited from a pool of $9^{\text {th }}$ and $10^{\text {th }}$ grade students $(N=12,970)$ from 16 Chicago suburban-metropolitan area schools. Of the participants screened, 11,718 (90.3\%) met inclusion criteria for the larger parent study based on smoking history and patterns, and 3,695 of these (31.5\%) were invited to participate in the longitudinal study. Of those who were invited, 1,344 (36.4\%) were willing to participate, and 1,263 (93.8\%) completed the baseline measurement wave. Attrition in the current study was minimal. At the 15month follow-up $1128(89.3 \%)$ and at the 24-month follow-up 1,147 adolescents (90.8\%) participated in data collection.

Of the 1,147 adolescents who participated in the 24-month data collection, 772 met criteria for the current study (i.e., stated that they drink, have drunk alcohol within the past three months, and had no missing data on the variables of interest). Participants were primarily White (78.6\%), 17.4\% were Black, $15.8 \%$ were Hispanic, $4.5 \%$ were Asian, $2.3 \%$ were Native Hawaiian/Pacific Islander, and 3.8\% were American Indian/Alaska Native. Please refer to Tables 2 and 3 for demographic and alcohol use characteristics of the sample. 


\section{C. $\quad$ Procedures}

The "Health Habits" portion of the longitudinal study used self-report, paper-and-pencil questionnaires, which were mailed to the participants a few weeks prior to each data collection wave. The participant was instructed to complete the questionnaire and bring it to an appointment set up by the field team. Participants received a payment of $\$ 20$ for their completed questionnaire at 15 -months and $\$ 40$ at 24 -months.

\section{Measures $^{2}$}

Demographic information was assessed using paper-and-pencil self-report questionnaires.

Demographic information included gender, grade, age, and race/ethnicity. Adolescent depressive symptoms were assessed via the Center for Epidemiological Studies Depression inventory (CES-D; Radloff, 1977). The CES-D is a widely used 20-item measure that assesses the frequency of depressive symptoms experienced in the past week, from 0 (rarely or none of the time) to 3 (most or all of the time). The CES-D assesses specific areas of depressive symptomatology, including depressed affect, happiness, somatic symptoms and psychomotor retardation, and interpersonal difficulties; responses are summed to create an overall scale score. Research supports the validity and utility of the CES-D to measure depressive symptoms in high school adolescents (Lewinsohn, Rohde, \& Seeley, 1998; Radloff, 1991; Roberts, Andrews, Lewinsohn, \& Hops, 1990), and suggests that the clinical cutoff for adolescents is 22 for boys and 24 for girls, versus the adult cutoff of 16 (Lewinsohn et al., 1998). Coefficient alpha in the current sample $=.89$. Data were used from the 15 - and 24-month questionnaires.

\footnotetext{
${ }^{2}$ Please see Table 1 for a summary of the timeline of measures/variables used in the current study.
} 
Adolescent anxiety symptoms were assessed with 12 items from the Mood and Anxiety Symptom Questionnaire (MASQ; Watson \& Clark, 1991; Watson, Weber, Assenheimer, Clark, Strauss, \& McCormick, 1995), a 90-item measure that assess symptoms of anxiety and mood disorders. The MASQ was constructed to test the tripartite model of depression and anxiety (Watson \& Clark, 1991), and contains three subscales assessing: (1) general distress symptoms that are theorized as nonspecific to depression or anxiety (e.g., "feeling nervous" and "unable to relax"); (2) anxious arousal, with items addressing specific anxiety symptoms of somatic tension and hyperarousal (e.g., "feeling dizzy or lightheaded"; "muscles were tense or sore"); and (3) anhedonic depression symptoms specific to depressive disorders (e.g., "was proud of myself"; "felt like I had a lot of energy", reverse scored). The shortened version of the scale used in the current study contains items from each of the three MASQ subscales. For the purposes of this study, only questions from the first two subscales will be used. Adolescents rated the extent to which they had experienced each symptom in the past week according to a 5-point Likert-type scale, ranging from 1 (not at all) to 5 (extremely). Item scores were summed to yield a scale score, with strong internal reliability (coefficient alpha in the current sample $=.81$ ). Research supports the reliability and validity of the MASQ with adults (Keogh \& Reidy, 2000; Reidy \& Keogh, 1997) and with youth (Richey, Lonigan, \& Phillips, 2002). Data were used from the 15- and 24-month questionnaires.

Peer social support and sense of belonging was assessed via Will's Social Support Scale (Wills et al., 2004), a 4-item scale with high internal reliability (coefficient alpha $=.94$ ). Items from this scale tap into the level of connection felt with peers, with responses on a Likert-type scale from 1 (never) to 5 (always). Items include how often youth discuss feelings with a friend, get emotional support from a friend, get sympathy and understanding from a friend, and talk with a friend 
about how they feel. Factor analyses on the current sample confirmed the unidimensional structure of the scale. Items are summed to yield a total score of peer support; higher scale scores indicate greater perceived peer support and belonging. Data were used from the 15- and 24month questionnaires.

Support and belonging to risky peer networks was assessed with a modified Social Network Inventory for Tobacco Smokers (SNITS). The SNITS is a 16-item inventory that measures whether participants receive either emotional or belonging support from individuals who smoke (Mermelstein et al., 1986). This inventory was modified to include other risky behaviors of peers (alcohol use, trouble at school, grades). Items ask about friends who provide either emotional support or companionship and whether these friends engage in problem (e.g., smoking, drinking) or non-problem (e.g., getting good grades) behaviors. Response options range from 0 (0 people) to 5 (5 or more people). Factor analyses on SNITS data from the longitudinal study identified two factors: 1) problem behavior items and 2) non-problem behavior items. Higher scores on both factors indicate receiving support from a higher number of peers who engage in problem or non-problem behaviors. These two scales have good internal reliability (coefficient alpha $=.85$ and .71, respectively). For purposes of the current study, only the problem-behavior network items will be utilized. Data were used from the 15- and 24-month questionnaires. Adolescent novelty seeking was assessed with 8 items from the Tridimensional Personality Questionnaire (TPQ; Cloninger, 1987), adapted for adolescents (Wills, Vaccaro, \& McNamara, 1994). The scale addresses personality characteristics such as seeking thrills and excitement and preferring to act on feelings of the moment, without regard for rules and regulations (e.g., "I often try new things for fun or thrills"; "I often follow my instincts without stopping to think about details"). Items are scored on a 4-point Likert-type scale, ranging from 1 (not at all true of 
me) to 4 (pretty true of me), with a total score formed by averaging items such that higher scores reflect higher levels of novelty seeking; coefficient alpha $=.73$. Data were used from the 15 month questionnaire.

Drinking motives were assessed using the 15-item Drinking Motives Scale, which assesses three main reasons for drinking - coping (e.g., "to forget your worries"), social (e.g., "because it makes a social gathering more enjoyable"), and enhancement (e.g., "to get high"; Cooper et al., 1992). Students were asked the frequency for which they drank for a specific reason and rated their answering using a 4-point scale ( $1=$ "almost never/never" to 4 = "almost always"). A mean score was calculated for each of the three scales. This measure has good internal consistency (Cronbach's alphas ranging between .77 and .85) and a confirmatory factor analysis has supported a three-factor solution for this measure (Cooper et al., 1992). With the present data, coefficient alpha was high for all three scales $(\alpha=.83-.90)$. Data were used from the 24-month questionnaire.

Binge Drinking was measured by using a quantity variable from an alcohol problem scale. Female binge drinkers were defined as those who drank an average of four or more drinks on drinking occasions and males were defined as those who drank an average of five or more drinks on drinking occasions. All other drinkers (i.e., those who reported that they drink alcohol and had drunk within the past three months) were classified as "Non-Binge Drinkers". Data were used from the 24-month questionnaire.

Alcohol-related problems were assessed using items adopted from a multigenerational longitudinal study of children of alcoholics (Colder \& Chassin, 1999). The original measure contained 19 items that referred to negative social consequences and dependency symptoms of alcohol and drug use, which were modeled after DSM diagnostic criteria for substance use and 
dependence. Participants in the current study responded to 6 dichotomous items (yes/no), 5 of which were taken directly from the original 19 items and one item that had been created from 2 of the original 19 items. Participants were asked to respond to whether any of the 6 negative consequences had happened to them within the past year. These negative consequences in relation to alcohol and drug use included: "had problem with, or complaints from, your family or friends", "been in trouble at school or work", "been in trouble with the police", "had an accident or injury", “awakened the morning after and found that you couldn't remember things that had happened the night before", and "ended up drinking/using more than you had expected to when you began". A mean score was calculated to create an alcohol-related problem variable (coefficient alpha $=.73$ at 24-months). Data were used from the 24-month questionnaire. 


\section{RESULTS}

\section{A. Preliminary Analyses}

Demographic information about the entire sample can be found in Table 2. The mean age of the sample was 17.6 years. Of the total sample, $55.7 \%$ met the criteria as binge drinkers. Similarly, $55.1 \%$ and $56.6 \%$ of females and males met criteria as binge drinkers, respectively. Alcohol use characteristics of the sample can be found in Table 3. Overall, binge drinkers reported drinking alcohol more frequently than non-binge drinkers. Specifically, female and male non-binge drinkers most commonly reported drinking alcohol "once a month or less" over the past three months, whereas female binge drinkers most often reported drinking "more than once a month, but less than once per week" and male binge drinkers most often reported drinking "once or more a week, but not every day". As expected, average quantity of alcohol consumed also varied by gender and drinking status. Female non-binge drinkers most commonly reported drinking an average of three drinks, and male non-binge drinkers most commonly reported drinking an average of three and four drinks. Interestingly, female binge drinkers most often reported drinking an average of four drinks, whereas male binge drinkers most often reported drinking six or more drinks on average.

Descriptive statistics for the main variables used in the current study are shown in Table 4. As can be seen, t-tests showed that females had significantly higher rates of depression and anxiety, as well as more perceived friend support. Males endorsed significantly higher rates of associating with a problem-behavior network and drinking for social reasons. Furthermore, binge drinkers reported slightly more perceived friend support than non-binge drinkers. Binge drinkers also endorsed drinking alcohol for coping and enhancement reasons significantly more than nonbinge drinkers and had significantly higher rates of alcohol-related problems. 
Correlations for all psychosocial variables at 24 months can be found in Table 5. As expected, depression was significantly correlated with anxiety, and all of the drinking motives were also correlated in expected directions. Friend support was also negatively correlated with depression, and novelty seeking was positively correlated with friend support and belonging to a problem-behavior network. All of the measures were positively correlated with alcohol-related problems, except for friend support (which was not significantly related in either direction). While most of the correlations remained the same, there were some differences found when the correlations were examined separately by drinking status (e.g., binge vs. non-binge drinkers; see Table 6). For non-binge drinkers, novelty seeking and enhancement motives were positively correlated with depression, and friend support was negatively correlated with depression. In addition, novelty seeking was positively correlated with anxiety for non-binge drinkers, whereas social motives were positively correlated with anxiety for binge drinkers. Novelty seeking was positively correlated with coping motives only for the non-binge drinkers. Finally, only enhancement motives were positively correlated with friend support but only for binge drinkers.

\section{B. Overview of Data Analyses}

\section{Path Analyses}

Two sets of nested structural models were tested. The first set examined cross-sectional, structural relations among model variables. This model included five exogenous variables (depression, anxiety, novelty seeking, friend support, and problem-behavior network) and four endogenous variables (coping, enhancement, and social motives and alcohol-related problems). The second set of nested models examined the same variables longitudinally in which 15-month exogenous variables were entered into the model predicting 24-month drinking motives and 
alcohol-related problems. The first model tested in each set examined associations hypothesized by Cooper et al. (1995) and Read et al. (2003). The second model in each set is the revised model, with additional non-hypothesized paths based upon the modification indices of AMOS.

\section{2. $\quad$ Model Specification}

All models were estimated from covariance matrices using a maximum likelihood estimation procedure with manifest (measured) variables. Covariances were estimated among all exogenous variables, as well as the drinking motives error variables. In longitudinal models, 15month alcohol-related problems were controlled for by including it as an exogenous variable with paths estimated to 24-month drinking motives and alcohol-related problems.

\section{3. $\quad$ Evaluation of Model Fit}

Model fit was evaluated by using omnibus chi-square tests and goodness-of-fit and comparative fit indices for all of the nested structural equation models. Models were compared by examination of chi-square difference scores and Type II indices of incremental fit.

\section{Cross-Sectional Path-Analytic Models}

Cross-sectional models were tested based upon the findings of Cooper et al. (1995) and Read et al. (2003) to evaluate how these motivational models would replicate among adolescent binge and non-binge drinkers. First, four groups were created based upon gender and binge status (female binge drinkers, female non-binge drinkers, male binge drinkers, and male non-binge drinkers). Next, two cross-sectional models were tested for each group: one positing full mediation by drinking motives (i.e., the hypothesized cross-sectional model) and the other allowing for estimation of direct paths suggested by the modification indices to improve overall model fit (as indicated by goodness-of-fit indices). Because the overall fit of the hypothesized model was not good (see Table 7), the fit associated with including the paths suggested by the 
modification indices were examined. Finally, multi-group analyses were conducted to determine significant differences between binge and non-binge drinkers for each gender (e.g., binge vs. non-binge drinking females and binge vs. non-binge drinking males). Due to the poor fit of the hypothesized model, the results presented below are based upon the revised models due to the improved model fit as assessed by chi-square difference tests (see Table 7).

\section{1. $\quad$ Females}

To improve model fit, five additional relationships were added to the hypothesized model. Specifically, paths were estimated from anxiety, peer support, and problem-behavior directly to alcohol-related problems. In addition, the paths from novelty seeking to social motives and from problem-behavior network to enhancement motives were also estimated (see Figure 2). While the chi-square of the model's fit remained significant for female binge drinkers, fit indices indicate that it this model fits the data significantly better for this group and that the overall fit of the revised model was moderate (Table 7). For non-binging females, the overall fit was very good.

For binging females, the paths from depression to coping motives and from anxiety directly to alcohol-related problems were significant. Novelty seeking was significantly related to social motives, and enhancement motives mediated the relationship between novelty seeking and alcohol-related problems. Peer support was negatively associated with alcohol-related problems. Finally, the relationships between problem-behavior network and both social motives and alcohol-related problems were significant. This model explained $29 \%$ of the variance in alcohol-related problems.

For non-binging females, coping motives mediated the relationship between depression and alcohol-related problems. In addition, problem-behavior network was significantly related to 
enhancement and social motives, as well as alcohol-related problems. This model explained $28 \%$ of the variance in alcohol-related problems.

A multi-group analysis was then computed to compare the differences in the revised models between female binge and non-binge drinkers. The results indicated that the significant differences $(p<.05)$ between the groups were the relationships between coping motives and alcohol-related problems, as well as enhancement motives and alcohol-related problems.

\section{Males}

Again, to improve model fit, six additional relationships were added to the hypothesized model. Specifically, paths were estimated from depression and anxiety to enhancement motives, from anxiety to social motives, and from novelty seeking to social motives. In addition, paths were estimated from problem-behavior network to enhancement motives and directly to alcoholrelated problems (see Figure 3). While the chi-square for the revised model remained significant for the male binge drinkers, the new model was a significantly better fit for the data (as indicated by a chi-square difference test; see Table 7) and indicated a moderate fit. However, despite being a significantly better fit for non-binging males, fit indices indicate that it is not a good, or even moderate, fit for this group. Multi-group analyses were not completed to compare differences between binge and non-binge drinking males due to the poor fit of the model for non-binging males. Only the results for the binging males are reported.

For binging males, the paths between depression and anxiety and coping motives were significant. Anxiety was also significantly related to social motives. In addition, the paths between novelty seeking and both enhancement and social motives were significant. Problembehavior network was significantly related to enhancement motives and alcohol-related 
problems, and social motives mediated the relationship between problem-behavior network and alcohol-related problems. This model explained $23 \%$ of the variance in alcohol-related problems.

\section{Longitudinal Path-Analytic Models}

Longitudinal models were tested to determine if the 15-month exogenous variables of depression, anxiety, novelty seeking, friend support, and problem-behavior network would predict the 24-month drinking motives, and in turn, 24-month alcohol-related problems. In addition, 15-month alcohol-related problems was entered into the model as an exogenous variable. Again, two models were tested for each of the four groups: one positing full mediation by drinking motives (e.g., the hypothesized longitudinal model) and the other allowing for estimation of direct paths suggested by the modification indices to improve overall model fit. Again, because the overall fit of the hypothesized model was not good (see Table 8), the fit associated with including the paths suggested by the modification indices was examined. Multigroup analyses were conducted to determine significant differences between binge and nonbinge drinkers for each gender (same as was done for the cross-sectional analyses). The results presented below are based upon the revised models due to generally improved model fit as assessed by chi-square difference tests (see Table 8).

\section{1. $\quad$ Females}

To improve model fit, five additional relationships were added to the hypothesized model. Specifically, paths were estimated from 15-month alcohol-related problems to coping, enhancement, and social motives. In addition, paths were estimated from novelty seeking to social motives and from problem-behavior network to enhancement motives (see revised model; Figure 4). The overall fit of the model for binging and non-binging females was very good (Table 8). 
For binging females, novelty seeking was significantly related to social motives, and enhancement motives mediated the relationship between novelty seeking and alcohol-related problems. In addition, 15-month alcohol-related problems were significantly related to all of the drinking motives, as well as 24-month alcohol-related problems. This model explained $36 \%$ of the variance in 24-month alcohol-related problems.

For non-binging females, coping motives mediated the relationship between depression and alcohol-related problems. In addition, problem-behavior network was significantly related to enhancement motives, and social motives were related to alcohol-related problems. Again, the 15-month alcohol-related problems were significantly related to all of the drinking motives, as well as 24-month alcohol-related problems. This model explained $43 \%$ of the variance in $24-$ month alcohol-related problems.

Similar to the cross-sectional multi-group analysis, there were significant differences $(\mathrm{p}<$ .05) between the binge/non-binge drinking groups. Specifically, the relationships between coping motives and alcohol-related problems, as well as enhancement motives and alcohol-related problems, were significantly different.

\section{Males}

To improve model fit, five additional relationships were added to the hypothesized model (see revised model; Figure 5). Specifically, paths were estimated from depression and anxiety to enhancement motives, from novelty seeking to coping and social motives, and from 15-month alcohol-related problems to enhancement motives. The overall fit of the revised model was very good for both binging and non-binging males (Table 8).

For binging males, the path between depression and coping motives was significantly related. In addition, novelty seeking was significantly related to both enhancement and social 
motives. Social motives also mediated the relationship between problem-behavior network and alcohol-related problems. Finally, 15-month alcohol-related problems were significantly related to 24 -month alcohol-related problems. This model explained $27 \%$ of the variance in 24 -month alcohol-related problems.

For non-binging males, the paths between anxiety and both coping and enhancement motives were significant. In addition, novelty seeking was significantly related to all three drinking motives (coping, enhancement, and social). Finally, 15-month alcohol-related problems were significantly related to 24-month alcohol-related problems. This model explained $33 \%$ of the variance in 24-month alcohol-related problems.

Multi-group analyses indicated significant differences $(\mathrm{p}<.05)$ between the binge and non-binge drinking groups. Specifically, the relationships between anxiety and enhancement motives and novelty seeking and coping motives were significantly different.

\section{E. $\quad$ Exploratory Cross-Sectional Moderated-Mediation Analyses}

Significant differences in motives between binge and non-binge drinkers were difficult to explore in the cross-sectional analyses, likely due to poor or moderate model fit for three of the four groups. Thus, a series of moderated mediation analyses were conducted to possibly better examine the differences in drinking motives between binge and non-binge drinkers. Specifically, each drinking motive was examined separately (i.e., three mediational analyses were conducted) and then multi-group analyses were performed to determine if binge status (binge vs. non-binge drinker) moderated each mediational analysis. These analyses were conducted using bootstrap mediation techniques in AMOS separately for males and females. Each analysis included the exogenous variable(s) hypothesized to relate to their specific drinking motive, as well as to 
alcohol-related problems. Models and significant pathways are reported in Figures 6 and 7 for females and males, respectively.

\section{1. $\quad$ Females}

Coping motives fully mediated the relationship between depression and alcohol-related problems for non-binge drinking females but not for binge drinkers. In addition, while coping motives did not mediate the relationship between anxiety and alcohol-related problems for nonbinge drinking females, there is evidence for a partial mediation for binge drinkers. Specifically, the relationships between anxiety and coping motives and, in turn, coping motives and alcoholrelated problems were significant. However, the direct relationship between anxiety and alcoholrelated problems remained significant when the mediator was entered into the model. The pathway between anxiety and alcohol-related problems was significantly different for binge and non-binge drinkers.

As expected, enhancement motives mediated the relationship between novelty seeking and alcohol-related problems. There is evidence of full mediation for both binge and non-binge drinking females. None of the pathways significantly differed between binge and non-binge drinkers.

Social motives did not mediate the relationship between peer support and alcohol-related problems for binge or non-binge drinking females, as peer support was not significantly related to social motives or alcohol-related problems. However, peer support was negatively associated with alcohol-related problems for the binge drinking females. Interestingly, the analyses revealed a partial mediation for binge drinkers and non-binge drinkers for the mediational analysis involving problem-behavior network, social motives, and alcohol-related problems. For both binge and non-binge drinkers, problem-behavior network was significantly related to coping 
motives, and, in turn, coping motives was significantly related to alcohol-related problems. However, the relationship between problem-behavior network and alcohol-related problems remained significant for binge drinkers. None of the pathways significantly differed between binge and non-binge drinkers.

\section{Males}

Coping motives fully mediated the relationships between depression and alcohol-related problems for both binge and non-binge drinking males. In addition, for binging males, coping motives partially mediated the relationship between anxiety and alcohol-related problems, as the relationship between anxiety and alcohol-related problems remained significant when the mediator was entered into the model. None of the pathways differed significantly between binge and non-binge drinkers.

Again, as expected, enhancement motives mediated novelty seeking and alcohol-related problems for both binge and non-binge drinking males. As the relationship between novelty seeking and alcohol-related problems was no longer significant once the mediator was entered into the model, there is evidence of full mediation for both groups. There were no significant differences in the relationships of any of the variables for binge and non-binge drinkers.

Social motives partially mediated the relationship between problem-behavior network and alcohol-related problems for binge-drinking males; the relationship between problembehavior network and alcohol-related problems remained significant when the mediator was entered into the model. Interestingly, while problem-behavior network was not significantly related to social motives for non-binge drinkers, it was significantly related to social motives and social motives were related alcohol-related problems. None of these pathways significantly differed between binge and non-binge drinking males. 


\section{F. Exploratory Longitudinal Moderated-Mediation Analyses}

A series of moderated mediation analyses were conducted examine the differences in drinking motives between binge and non-binge drinkers longitudinally. Again, each drinking motive was examined separately (i.e., three mediational analyses were conducted) and then multi-group analyses were performed to determine if binge status (binge vs. non-binge drinker) moderated each mediational analysis. As done previously, these analyses were conducted using bootstrap mediation techniques in AMOS separately for males and females. Each analysis included the 15-month exogenous variable(s) hypothesized to relate to their specific drinking motive, as well as to alcohol-related problems. Fifteen-month alcohol-related problems were added into each model as an exogenous variable. Models and significant pathways are reported in Figures 8 and 9 for females and males, respectively.

\section{1. $\quad$ Females}

Coping motives partially mediated the relationship between 15 -month depressive symptoms and 24-month alcohol-related problems, but only for non-binge drinking females, such that the relationship between depression and alcohol-related problems remained significant after adding coping motives into the model. Coping motives also fully mediated the relationship between 15 -month anxiety symptoms and 24-month alcohol-related problems, but only for binge drinking females. There were significant differences in two of the model's paths (depression to coping motives and anxiety to coping motives), suggesting significant differences in these two mediational analyses.

As expected, enhancement motives fully mediated the relationship between novelty seeking and alcohol-related problems for both binge and non-binge drinking females. However, it is noted that the mediation remained when 15-month alcohol-related problems were entered 
into the model. None of the pathways differed significantly between female binge and non-binge drinkers.

Social motives fully mediated the relationship between 15 -month problem-behavior network and 24-month alcohol-related problems for both female binge and non-binge drinkers. In addition, while 15-month peer support was not significantly related to 24-month alcoholrelated problems for either binge or non-binge drinkers, the multi-group analysis showed that this pathway significantly differed between the two groups.

\section{2. $\underline{\text { Males }}$}

Coping motives partially mediated the relationship between 15 -month depressive symptoms and 24-month alcohol-related problems (the direct relationship between depression and alcohol-related problems remained significant) for non-binge drinking males. In addition, 15-month anxiety symptoms were significantly related to 24-month alcohol-related problems for non-binge drinking males, and this pathway was significantly different for binge and non-binge drinkers.

Similar to previous analyses, enhancement motives fully mediated the relationship between novelty seeking and alcohol-related problems. Like the females, these relationships remained significant when 15-month alcohol-related problems were entered into the model. None of the pathways significantly differed between the two groups.

Social motives fully mediated the relationship between 15 -month problem-behavior network and 24-month alcohol-related problems, but only for binge drinkers. None of the pathways in this model significantly differed between binge and non-binge drinking males. 


\section{DISCUSSION}

The main goal of this study was to expand upon the work of Cooper et al. (1995) and Read et al. (2013) by examining the differences in a motivational model of alcohol use between binge and non-binge drinking adolescents. Specifically, the present study sought to build on this prior literature by examining how negative affect, novelty seeking, and peer factors may lead to certain motivations for drinking, how these motivations may differ between binge and non-binge drinkers, and how the proposed relationships differ between males and females among a sample of adolescents. Furthermore, this study sought to test whether the proposed model would replicate in longitudinal analyses.

\section{A. The Hypothesized Model}

It was first hypothesized that certain psychosocial antecedents would be associated with specific drinking motives (see Figure 1), and that the drinking motives would be associated with

alcohol-related problems, as measured by participants' endorsement of negative consequences of alcohol/drug use that happened within the past year (e.g., problems/complaints from family or friends, being in trouble at school or work, being in trouble with the police, had an accident or injury, unable remember events of the previous night, and drinking/using more than intended). For both the cross-sectional and longitudinal analyses, the hypothesized models were not a good fit for the data; however, adjusted models , created by adding paths from the psychosocial antecedents to both drinking motives and alcohol-related problems based upon the modification indices, provided a good fit for the majority of analyses conducted. Consistent with Cooper et al. (1995) and Read et al. (2003), these results continue to support the theory that that there are multiple etiological pathways to alcohol-related problems and that these pathways are mediated by drinking motives. Specifically, as predicted, negative affect, novelty seeking, and peer factors 
were related to both drinking motives and alcohol-related problems; however, the significance and strength of these relationships varied by gender and binge status. Furthermore, similar to the findings of Read et al. (2003), additional relationships suggested by the modification indices in the present study indicated that many of the psychosocial antecedents were not specific to only one drinking motive as hypothesized and were often related to other motives, depending on gender and drinking status.

\section{B. Motivational Differences between Binge and Non-Binge Drinkers}

\section{1. $\quad \underline{\text { Negative Affect }}$}

Results from the cross-sectional analyses revealed that depression was directly related to coping motives (but not alcohol-related problems) for binge drinking males and females. These results held longitudinally, but only for binge-drinking males, such that depressive symptoms at 15-months led to drinking for coping reasons at 24-months (but not 24-month alcohol-related problems). Furthermore, the cross-sectional analyses showed that depression demonstrated an indirect association with alcohol-related problems via coping motives for non-binge drinking females. This relationship was replicated longitudinally, such that for non-binge drinking females, depression at 15 months was found to be indirectly related to alcohol-related problems at 24-months through coping motives (reported at 24-months). These results indicate that while binge drinkers may drink alcohol to cope with their feelings of depression, drinking for these reasons is not necessarily associated with alcohol-related problems.

The cross-sectional moderated-mediation analyses showed that depression was indirectly related to alcohol-related problems through coping motives for male binge drinkers and both male and female non-binge drinkers (but not for female binge drinkers). Interestingly, these relationships were also found longitudinally, but only for non-binge drinking males and females. 
Taken together, these results suggest that drinking to cope with feelings of depression may have deleterious outcomes, particularly for non-binge drinkers.

Anxiety was directly related to alcohol-related problems for female binge drinkers. Interestingly, anxiety was directly related to both coping and social motives for binge-drinking males. As social motives were related to alcohol-related problems for this particular group, there is some support for a meditational role for social motives between anxiety and alcohol-related problems. None of these cross-sectional results were replicated longitudinally; however, anxiety at 15-months was related to both coping and enhancement motives for non-binging males, meaning that this particular group is likely engaging in alcohol use to reduce their symptoms of anxiety for both internal negative (coping) and positive (enhancement) reinforcement.

The cross-sectional moderated-mediation analyses gave partial support for the indirect role of coping motives between anxiety and alcohol-related problems but only for male and female binge drinkers. Conversely, the longitudinal moderated-mediation analyses showed that 15-month anxiety symptoms were indirectly related to 24-month alcohol-related problems via 24-month coping motives for binging females. Finally, 15-month anxiety was directly related to 24-month alcohol-related problems for non-binging males.

These results are consistent with the literature that suggests that there are direct and indirect (via drinking motives) relationships between specific types of negative affect and alcohol-related problems (Cooper et al., 1995; Read et al., 2003; Wills et al., 1996; Wills et al., 1999; Wills et al., 2001; Windle \& Windle, 1996). In addition, consistent with previous literature (Cooper et al., 1992; Cooper, 1994; Kuntsche, Knibbe, Gmel, \& Engels, 2005; Windle \& Windle, 1996), the moderated-mediation analyses showed that drinking to cope with negative affective states was associated with alcohol-related problems. However, the results from the 
present study show that these relationships varied by gender and drinking status among this sample of adolescents.

These results also further Husson and Chassin's (1994) previous research, stating that depression and anxiety had unique effects with alcohol use, by supporting the importance of testing the differences in these relationships among different forms of negative affect.

Furthermore, there is some evidence that anxiety may have a unique relationship with drinking socially among binge-drinking males. Thus, as males tend to engage in binge drinking to gain peer approval (Liu \& Kaplan, 1996), it is possible that they are using the alcohol to alleviate anxiety associated with the desire to "fit in" with their peers, as Kaplow et al. (2001) has previously theorized.

The longitudinal results indicate that negative affect is an important predictor of drinking for coping reasons (and enhancement for males), as well as alcohol-related problems for the nonbinge drinkers. Cooper et al. (1995) and Read et al. (2003) both found that coping motives were directly related to alcohol-related problems and not via alcohol use (defined by quantity and frequency). Thus, it is understandable why these relationships were found among the non-binge drinkers, and suggests that teaching better, more adaptive coping strategies for reducing negative affective states is an important area to target for alcohol interventions for all adolescents.

\section{Temperament}

One of the most striking results from the cross-sectional path analyses was the significant difference between the meditational role of enhancement motives between novelty seeking and alcohol-related problems for females. Specifically, novelty seeking was indirectly related to alcohol-related problems through enhancement motives for female binge drinkers but not for female non-binge drinkers. This difference is likely because drinking for enhancement reasons is 
associated with heavier drinking (i.e., larger quantities of alcohol use) and drinking until drunk (Cooper et al., 1992; Cooper, 1994; Ham \& Hope, 2003).

While novelty seeking was directly related to enhancement motives for all males, enhancement motives were not related to alcohol-related problems for males. However, novelty seeking was related to social motives for males, which may suggest a possible meditational role for social motives between novelty seeking and alcohol-related problems for binge drinking males (found both cross-sectionally and longitudinally). These results suggest that male binge drinkers who score high on novelty seeking may be more likely to engage in alcohol use for both the internal (enhancement) and external (social) positive rewards, which may then lead to alcohol-related problems.

Interestingly, when enhancement motives were examined separately in the moderatedmediation analyses, they fully mediated the relationship between novelty seeking and alcoholrelated problems for all groups, regardless of gender or drinking status. These strong relationships remained even when 15-month alcohol-related problems (the strongest predictor of 24-month alcohol-related problems) were entered into the analysis. These results are consistent with the literature showing that enhancement motives are the most often reported reasons for alcohol use among adolescents (Terry-McElrath et al., 2009). Furthermore, while previous research has found that individuals who endorse enhancement motives are less likely to report alcohol-related problems (Cooper et al., 1992; Cooper, 1994), the current study found that among this sample of adolescents, those who scored highly on the personality trait of novelty seeking and who drank for enhancement reasons, have significantly higher rates of alcoholrelated problems. These results suggest that this personality trait is one of the strongest predictors 
of drinking (mainly for enhancement and social reasons), especially for males and bingedrinking females.

\section{3. $\quad \underline{\text { Peers }}$}

Peer support was not indirectly related to alcohol-related problems for any of the four groups examined in the current study in any of the analyses. The only significant finding for this psychosocial antecedent was that peer support was inversely related to alcohol-related problems for binge drinking females (found in the cross-sectional analyses). This finding suggests that peer support may be a protective factor for alcohol-related problems among this particular group.

Overall, both the cross-sectional path analyses and moderated-mediation analyses showed that associating with a problem-behavior network was directly associated with alcohol-related problems, regardless of gender or binge status, similar to findings of Read et al. (2003). However, the indirect relationships between peer associations and alcohol-related problems via drinking motives differed between the groups. Specifically, the path analyses showed that while associating with a problem-behavior network was directly related to social motives for both binge and non-binge drinking females, social motives were not related to alcohol-related problems. Conversely, for binge-drinking females, the longitudinal analyses showed that associating with a problem-behavior network at 15 months was indirectly related to 24-month alcohol-related problems via social motives (assessed at 24-months). For binge drinking males, associating with a problem behavior network was indirectly related to alcohol-related problems via social motives; this finding was replicated in the longitudinal analyses.

The cross-sectional moderated-mediation analyses gave some evidence for a meditational role for social motives between problem behavior network and alcohol-related problems for binge drinking males and females and for non-binge drinking females (but not for non-binge 
drinking males). These relationships held longitudinally for these three groups, such that 24month social motives mediated the relationship between socializing with a problem-behavior network at 15 months and later alcohol-related problems. Overall, for non-binge drinking males, there is evidence that associating with a problem behavior network and drinking for social reasons leads to alcohol-related problems; however, these results do not support the hypothesis that this particular psychosocial antecedent is the precursor to drinking for social reasons.

Of note, the pathways suggested by the modification indices in the cross-sectional analyses indicated that problem behavior network was also directly related to enhancement motives for both binge drinking males and non-binge drinking females; however, enhancement motives were not related to alcohol-related problems for these groups. These results suggest that socializing with a peer network that engages in a higher amount of problem behaviors may also lead certain adolescents to drink for the internal positive reinforcement that comes with alcohol use. This may be because peers who engage in more problem behaviors likely have more positive attitudes and expectancies towards alcohol use, which they may directly state and/or indirectly model to the adolescent (Borsari \& Carey, 2001).

These findings add to the mixed research about whether there is a relationship between social motives and alcohol-related problems (Bradizza et al., 1999; Cooper et al., 1992; Cooper, 1994). These results support the notion posited earlier that these adolescents are likely developing their drinking behaviors based upon their peers' actions and alcohol expectancies, which leads to motivations to drink for external positive rewards (and internal positive reinforcement for some), and possibly alcohol-related problems. Future research incorporating alcohol-expectancies of the adolescents and their peers is needed to determine the extent to which they play a role in these particular relationships. Furthermore, while the moderated- 
mediation results among the males are consistent with the literature showing that males may tend to engage in binge drinking to gain peer approval (Liu \& Kaplan, 1996), the results of this study indicate that females may engage in alcohol use (not just binge drinking) to gain peer approval. Yet overall, these results give continued support to Read et al.'s (2003) conclusions that social environment plays an important role in alcohol use and builds upon the previous research showing that it is also associated with alcohol-related problems.

\section{4. $\quad$ Previous Alcohol-Related Problems}

It is important to note that when the current models were modified several relationships were added in which 15-month alcohol-related problems were hypothesized to be related to drinking motives. For females, 15-month alcohol-related problems were directly related to all three drinking motives at 24-months (but not for males). Thus, for females, engaging in drinking behaviors that lead to significant consequences leads to drinking with a variety of different motivations that may lead to further alcohol-related problems.

\section{Strengths and Limitations}

One of the strengths of this study was the use of a sample that might be considered at somewhat of an elevated risk for alcohol use. The current sample was selected based on their smoking susceptibility or experience with smoking. Given that there is a high overlap between smoking and drinking as risk behaviors among adolescents (Johnson, Boles et al., 2000), it may be more likely to have the opportunity to observe drinking in this sample. Indeed, according to the Monitoring the Future Study (Johnston et al., 2013), 69\% of 12th graders reported ever using alcohol. In the current study, $91 \%$ of all 24 -month participants reported having at least one drink of alcohol in their lives. Moreover, $84 \%$ of these adolescents reported having at least one drink of alcohol in the past twelve months, and $66 \%$ had at least one drink of alcohol in the previous 
three months. According to these statistics, the rates of alcohol use among this sample were, in fact, what one would expect for being categorized as an "at risk" population. In general, the use of a high risk sample provided a greater likelihood of having adolescents who were engaging in alcohol use, thus, making it more likely to capture high rates of both binge and non-binge drinkers. As such, just over half of the current sample (56\%) met criteria as binge drinkers. Another strength of this study is the longitudinal aspect in which we were able to examine what psychosocial antecedents predicted later drinking motives and alcohol-related problems. It is noted that Read et al. (2003) designed their longitudinal analyses to determine if psychosocial antecedents were directly related to drinking motives at the first time point (the participant's freshman year of college), and in turn, if these variables predicted alcohol use and alcohol-related problems one year later. However, the longitudinal analyses in the current study included psychosocial antecedents from 15-months predicting both drinking motives and alcohol-related problems nine months later. Both analyses have their strengths and limitations and should be considered in model design for future research.

One limitation is that not all of the measures were aimed at a capturing adolescent alcohol use since the data for this study came from a tobacco use study. Specifically, binge drinking was measured by using a quantity variable of how much the adolescents drink on average. While using this variable may have been able to capture adolescents who have a pattern of binge drinking, it did not capture adolescents who binge drink on occasion (i.e., specifically asking them how many times they have drank $4 / 5$ or more alcoholic drinks at one time over a specific time period). However, the remainder of the alcohol data used for this study was specifically chosen to capture alcohol use and related problems among adolescents and the measures for the psychosocial antecedents were appropriate for this study and for the sample. 
Furthermore, the conceptual overlap in the alcohol variables used (e.g., binge drinking and alcohol-related problems) is noted, with their relationship being highly correlated.

Finally, one of the main questions that was to be addressed was how these hypothesized models differed among males and females. Since the models had to be modified separately by gender to achieve a good fit for the data, we were not able to run analyses that could determine whether the paths indicated significantly differed for males and females. While conclusions can be made about gender differences qualitatively based upon the results obtained, they were not able to be explored quantitatively.

\section{Conclusions and Future Directions}

Overall, the current study found that certain psychosocial antecedents were associated with alcohol-related problems both directly and indirectly via drinking motives, with some antecedents being associated with more than one drinking motive. Addressing the main purpose of the current study, there were significant differences between binge and non-binge drinkers, as well as between males and females. Specifically, depression was indirectly related to alcoholrelated problems via coping motives for binge drinkers, whereas anxiety was indirectly related to alcohol-related problems via coping motives for non-binge drinkers. In addition, the relationship between associating with a problem-behavior network and alcohol-related problems was mediated by social motives for all females but only for binge-drinking males. Finally, the meditational role of enhancement motives between novelty seeking and alcohol-related problems was found for all groups, regardless of binge status and gender.

Many future directions can be taken based upon these findings. First, the current results have many implications for future interventions for both adolescent binge and non-binge drinkers. Overall, this study gave further support that the psychosocial antecedents explored 
serve as particular risk factors for later motivations for alcohol use and alcohol-related problems. Therefore, interventions should be sure to incorporate strategies based upon each drinking motive (e.g., targeting negative affect coping skills, social norms correction approaches, etc.)

Second, future research focusing on motivations for alcohol use should include likely protective factors. This notion comes out of the current study's finding that peer support was not found to be positively related to either drinking for social reasons or to alcohol-related problems and was even found to be inversely related for binge drinking females in the cross-sectional analyses. Thus, the results of the current study contradict previous research showing that peer support may be a risk factor for alcohol use (Wills \& Vaughn, 1989; Wills et al., 2004). While much research has focused on the risk factors for adolescent binge drinking, future research should take the next step to identify protective factors.

Finally, as there is literature showing that coping (Pirkle \& Richter, 2006; Rutledge \& Sher, 2001; Schulenberg et al., 1996), enhancement (Cooper et al., 1992; Cooper, 1994; Ham \& Hope, 2003), and social (Bradizza et al., 1999) motives are important predictors of future binge drinking, drinking until drunk, and alcohol misuse, future research could expand upon the current study by including later binge drinking behavior. As the adolescents in the current study were upperclassmen in high school, the current motivational model could be expanded to explore whether these drinking motives not only lead to binge drinking in young adulthood but whether the drinking motives change over time. Finally, it would be interesting to examine how many of the adolescents who fell into the non-binge drinking group would later meet criteria as binge drinkers and if these possible changes differed by reported drinking motives. 
Figure 1. The Cross-Sectional Hypothesized Model

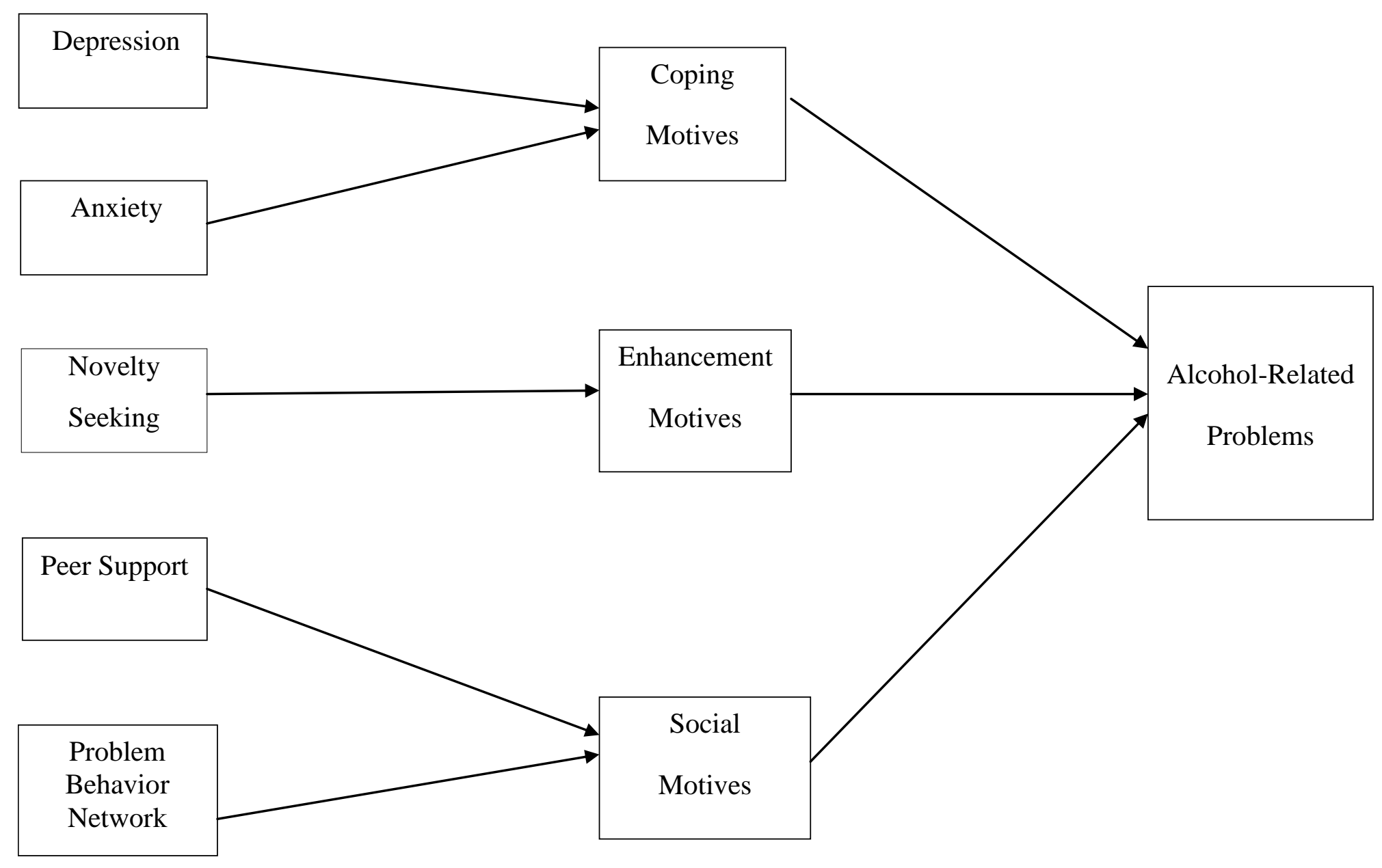


Table 1

Timeline of Measures/Variables Used

\begin{tabular}{|c|c|c|c|}
\hline Measure/Variable & Baseline & 15-Months & 24-Months \\
\hline Demographics & $\mathrm{X}$ & & \\
\hline CES-D & & $\mathrm{X}$ & $\mathrm{X}$ \\
\hline MASQ & & $X$ & $X$ \\
\hline Friend Support & & $X$ & $X$ \\
\hline SNITS & & $X$ & $\mathrm{X}$ \\
\hline Novelty Seeking & & $X$ & \\
\hline Drinking Motives & & & $\mathrm{X}$ \\
\hline Binge Drinking & & & $\mathrm{X}$ \\
\hline ADIS & & $X$ & $X$ \\
\hline
\end{tabular}

Note. CES-D, Center for Epidemiological Studies - Depression; MASQ, Mood and Anxiety Symptom Questionnaire; SNITS, Social Network Inventory for Tobacco Smokers; ADIS, Adolescent Alcohol- and Drug-Related Problems Scale. 
Table 2

Demographic and Binge Status of the Sample $(N=772)$

Total Sample

Female

Male

$(N=772)$ $(N=454)$ $(N=318)$

Demographics

Age

Female

White

African American

Hispanic/Latino

Asian

American Indian/Alaska Native

Native Hawaiian/Pacific Islander

Binge Status (24 Months)
$17.6( \pm .6)$

$454(58.8 \%)$

$607(78.6 \%)$

$134(17.4 \%)$

$122(15.8 \%)$

$35(4.5 \%)$

$29(3.8 \%)$

$18(2.3 \%)$

Non-Binge Drinkers

$342(44.3 \%)$

$204(44.9 \%) \quad 138(43.4 \%)$

Binge Drinkers

$430(55.7 \%)$

$250(55.1 \%)$

$180(56.6 \%)$ 
Table 3

Alcohol Use Characteristics of the Sample $(N=772)$

\begin{tabular}{|c|c|c|c|c|c|}
\hline & $\begin{array}{c}\text { Total } \\
\text { Sample } \\
(N=772) \\
\text { No. }(\%)\end{array}$ & $\begin{array}{c}\text { Female } \\
\text { Non-Binge } \\
\text { Drinkers } \\
(N=204)\end{array}$ & $\begin{array}{l}\text { Female } \\
\text { Binge } \\
\text { Drinkers } \\
(N=250)\end{array}$ & $\begin{array}{c}\text { Male } \\
\text { Non-Binge } \\
\text { Drinkers } \\
(N=138)\end{array}$ & $\begin{array}{c}\text { Male Binge } \\
\text { Drinkers } \\
(N=180)\end{array}$ \\
\hline \multicolumn{6}{|l|}{ Frequency } \\
\hline Once a month or less & $247(32.0 \%)$ & $123(60.3 \%)$ & $42(16.8 \%)$ & $61(44.2 \%)$ & $21(11.7 \%)$ \\
\hline $\begin{array}{l}\text { More than once a month, } \\
\text { but less than once per week }\end{array}$ & $304(39.4 \%)$ & $57(27.9 \%)$ & $126(50.4 \%)$ & $54(39.1 \%)$ & $67(37.2 \%)$ \\
\hline $\begin{array}{l}\text { Once or more a week, } \\
\text { but not every day }\end{array}$ & $220(28.5 \%)$ & $23(11.3 \%)$ & $82(32.8 \%)$ & $23(16.7 \%)$ & $92(51.1 \%)$ \\
\hline Every day & $1(0.1 \%)$ & $1(0.5 \%)$ & 0 & 0 & 0 \\
\hline \multicolumn{6}{|l|}{ Amount } \\
\hline 1 drink or less & $78(10.1 \%)$ & $57(27.9 \%)$ & -- & $21(15.2 \%)$ & -- \\
\hline 2 drinks & $98(12.7 \%)$ & $63(30.9 \%)$ & -- & $35(25.4 \%)$ & -- \\
\hline 3 drinks & $124(16.1 \%)$ & $84(41.2 \%)$ & -- & $40(29.0 \%)$ & -- \\
\hline 4 drinks & $140(18.1 \%)$ & -- & $98(39.2 \%)$ & $42(30.4 \%)$ & -- \\
\hline 5 drinks & $120(15.5 \%)$ & -- & $72(28.8 \%)$ & -- & $48(26.7 \%)$ \\
\hline 6 drinks & $70(9.1 \%)$ & -- & $36(14.4 \%)$ & -- & $34(18.9 \%)$ \\
\hline 6 or more drinks & $142(18.4 \%)$ & -- & $44(17.6 \%)$ & -- & $98(54.5 \%)$ \\
\hline
\end{tabular}


Table 4

Means and Standard Deviations of Main Variables for the Total Sample by Gender and Drinking Status

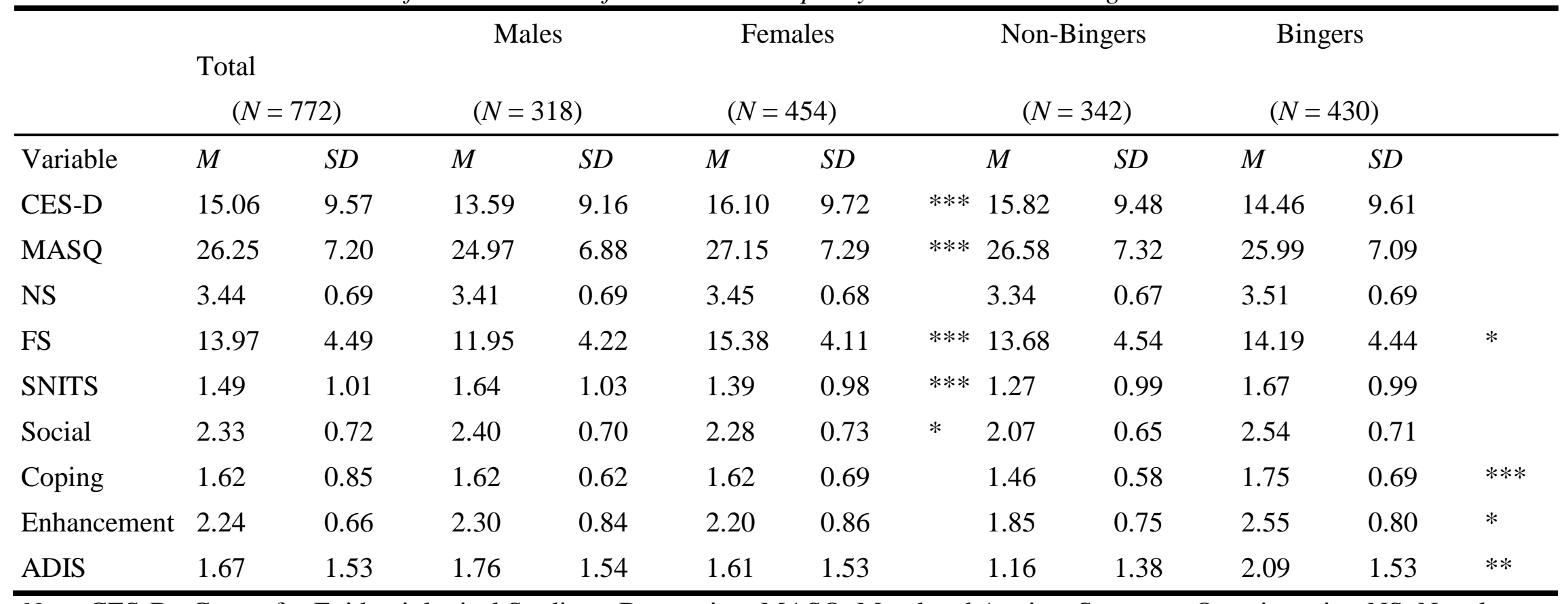

Note. CES-D, Center for Epidemiological Studies - Depression; MASQ, Mood and Anxiety Symptom Questionnaire; NS, Novelty Seeking; FS, Friend Support; SNITS, Social Network Inventory for Tobacco Smokers; ADIS, Adolescent Alcohol- and Drug-Related Problems Scale. For comparison of males versus females, ${ }^{*} p<.05 ; * * p<.01 ; * * * p .001$. 
Table 5

Correlations between All Variables for 24-Month Cross-Sectional Analyses $(N=772)$

\begin{tabular}{|c|c|c|c|c|c|c|c|c|}
\hline & CES-D & MASQ & $\mathrm{NS}$ & $\mathrm{FS}$ & SNITS & Social & Enhancement & Coping \\
\hline CES-D & --- & & & & & & & \\
\hline MASQ & $.734 * *$ & --- & & & & & & \\
\hline NS & .043 & .066 & --- & & & & & \\
\hline FS & $-.078 *$ & -.058 & $.134 * *$ & --- & & & & \\
\hline SNITS & .054 & .031 & $.218 * *$ & .023 & --- & & & \\
\hline Social & .044 & $.105 * *$ & $.287 * *$ & $.097 * *$ & $.305^{* *}$ & --- & & \\
\hline Enhancement & $.074 *$ & $.140 * *$ & $.274 * *$ & $.093 * *$ & $.294 * *$ & $.722 * *$ & --- & \\
\hline Coping & $.288 * *$ & $.311 * *$ & $.156^{* *}$ & .023 & $.188^{* *}$ & $.521^{* *}$ & $.631 * *$ & --- \\
\hline ADIS & $.100 * *$ & $.175^{* *}$ & $.200 * *$ & .010 & $.346^{* *}$ & $.433 * *$ & $.491 * *$ & $.371 * *$ \\
\hline
\end{tabular}

Note. CESD, Center for Epidemiological Studies-Depression; MASQ, Mood and Affect Symptom Questionnaire; NS, Novelty Seeking; FS, Friend Support; SNITS, Social Network Inventory for Tobacco Smokers; ADIS, Adolescent Alcohol- and Drug-Related Problems Scale; $* p<.05, * * p<.01$. 
Table 6

Correlations between All Variables for 24-Month Cross-Sectional Analyses by Drinking Status (binge [N=430] vs. non-binge [N=342] drinkers)

\begin{tabular}{|c|c|c|c|c|c|c|c|c|}
\hline & CES-D & MASQ & $\mathrm{NS}$ & $\mathrm{FS}$ & SNITS & Social & Enhancement & Coping \\
\hline CES-D & --- & & & & & & & \\
\hline MASQ & $\begin{array}{l}.723 * * \\
.747 * *\end{array}$ & --- & & & & & & \\
\hline NS & $\begin{array}{l}-.005 ; \\
.128 *\end{array}$ & $\begin{array}{l}.038 ; \\
.113 *\end{array}$ & --- & & & & & \\
\hline FS & $\begin{array}{l}-.045 ; \\
-.111 *\end{array}$ & $\begin{array}{l}-.028 ; \\
-.089\end{array}$ & $\begin{array}{l}.131 * * ; \\
.125^{*}\end{array}$ & --- & & & & \\
\hline SNITS & $\begin{array}{l}.066 \\
072\end{array}$ & $\begin{array}{l}.051 ; \\
.026\end{array}$ & $\begin{array}{l}.165 * * \\
.244 * *\end{array}$ & $\begin{array}{l}.010 \\
.015\end{array}$ & --- & & & \\
\hline Social & $\begin{array}{l}.049 \\
.102\end{array}$ & $\begin{array}{l}.169 * * ; \\
.067\end{array}$ & $\begin{array}{l}.255^{* *} ; \\
.272 * *\end{array}$ & $\begin{array}{l}.070 \\
.104\end{array}$ & $\begin{array}{l}.261 * * \\
.262^{* *}\end{array}$ & --- & & \\
\hline Enhancement & $\begin{array}{l}.051 ; \\
.198^{* *}\end{array}$ & $\begin{array}{l}.152 * * \\
.198 * *\end{array}$ & $\begin{array}{l}.252 * * \\
.238 * *\end{array}$ & $\begin{array}{l}.118^{*} ; \\
.024\end{array}$ & $\begin{array}{l}.232 * * \\
.250 * *\end{array}$ & $\begin{array}{l}.687 * * \\
.676 * *\end{array}$ & --- & \\
\hline Coping & $\begin{array}{l}.272 * * \\
372 * *\end{array}$ & $\begin{array}{l}.321 * * \\
.341 * *\end{array}$ & $\begin{array}{l}.068 ; \\
.235^{* *}\end{array}$ & $\begin{array}{l}.033 ; \\
-.021\end{array}$ & $\begin{array}{l}.154 * * \\
.154 * *\end{array}$ & $\begin{array}{l}.512 * * \\
.453 * *\end{array}$ & $\begin{array}{l}.614^{* *} ; \\
.607 * *\end{array}$ & --- \\
\hline ADIS & $\begin{array}{l}.109 * ; \\
.155^{* *}\end{array}$ & $\begin{array}{l}.237 * * \\
.143 * *\end{array}$ & $\begin{array}{l}.167 * * ; \\
.178 * *\end{array}$ & $\begin{array}{l}.018 \\
-.041\end{array}$ & $\begin{array}{l}.291 * * ; \\
.332 * *\end{array}$ & $\begin{array}{l}.388 * * ; \\
.346 * *\end{array}$ & $\begin{array}{l}.434 * * ; \\
.406 * *\end{array}$ & $\begin{array}{l}.309 * * ; \\
.362 * *\end{array}$ \\
\hline
\end{tabular}

Note. Results for binge drinkers are listed first. CESD, Center for Epidemiological Studies-Depression; MASQ, Mood and Affect Symptom Questionnaire; NS, Novelty Seeking; FS, Friend Support; SNITS, Social Network Inventory for Tobacco Smokers; ADIS, Adolescent Alcohol- and Drug-Related Problems Scale; * $p<.05, * * p<.01$. 
Table 7

Cross-Sectional Model Fit Indices

\begin{tabular}{|c|c|c|c|c|c|c|c|}
\hline & $\chi^{2}$ & $d f$ & GFI & CFI & CMIN & RMSEA & $R^{2} \mathrm{ADIS}$ \\
\hline \multicolumn{8}{|c|}{ Binging Females } \\
\hline Model 1 & 58.89 & 15 & .95 & .93 & 3.926 & .11 & .25 \\
\hline Model 2 & $24.79 *$ & 10 & .98 & .98 & 2.48 & .08 & .29 \\
\hline \multicolumn{8}{|c|}{ Non-Binging Females } \\
\hline Model 1 & 40.32 & 15 & .96 & .95 & 2.67 & .09 & .25 \\
\hline Model 2 & $10.92 *$ & 10 & .99 & .99 & 1.09 & .02 & .28 \\
\hline \multicolumn{8}{|c|}{ Binging Males } \\
\hline Model 1 & 82.25 & 15 & .92 & .85 & 5.49 & .16 & .17 \\
\hline Model 2 & $19.20 *$ & 9 & .98 & .98 & 2.13 & .08 & .23 \\
\hline \multicolumn{8}{|c|}{ Non-Binging Males } \\
\hline Model 1 & 58.85 & 15 & .92 & .87 & 3.92 & .15 & .13 \\
\hline Model 2 & $22.86^{*}$ & 9 & .97 & .96 & 2.54 & .10 & .17 \\
\hline
\end{tabular}

Note: GFI = goodness-of-fit index; $\mathrm{CFI}=$ comparative fit index; RMSEA = root mean square error of approximation. ${ }^{*} \chi 2$ difference test significant at $p<.05$ between Model 1 and Model 2. 
Figure 2. Cross Sectional Revised Model for Females

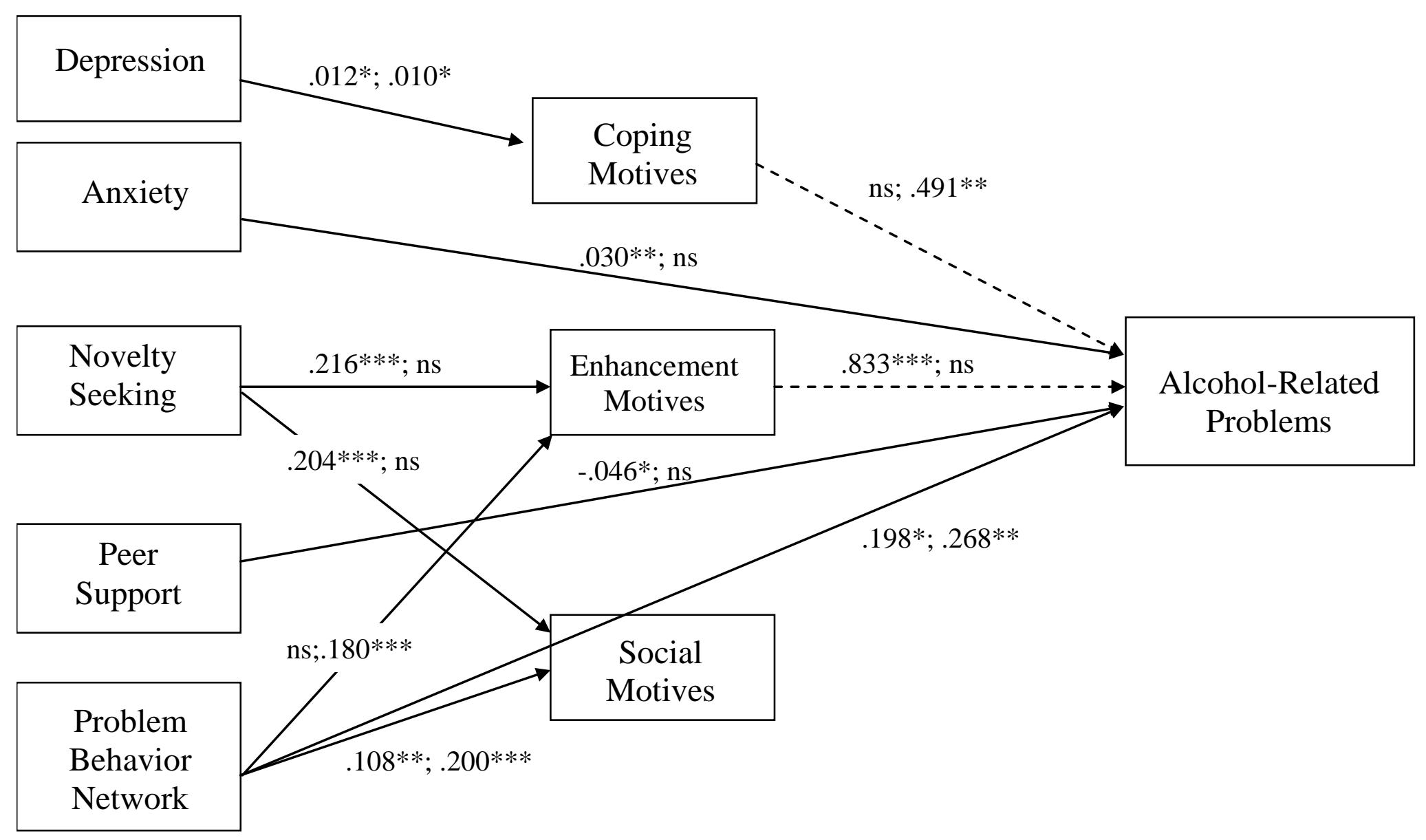

Note. Only significant structural paths are shown. $* \mathrm{p}<.05 ; * * \mathrm{p}<.01 ; * * * \mathrm{p}<.001$ for binge and non-binge drinking females, respectively. Dotted lines indicate those relationships that are significantly different $(\mathrm{p}<.05)$ between binge and non-binge drinkers. 
Figure 3. Cross Sectional Revised Model for Males

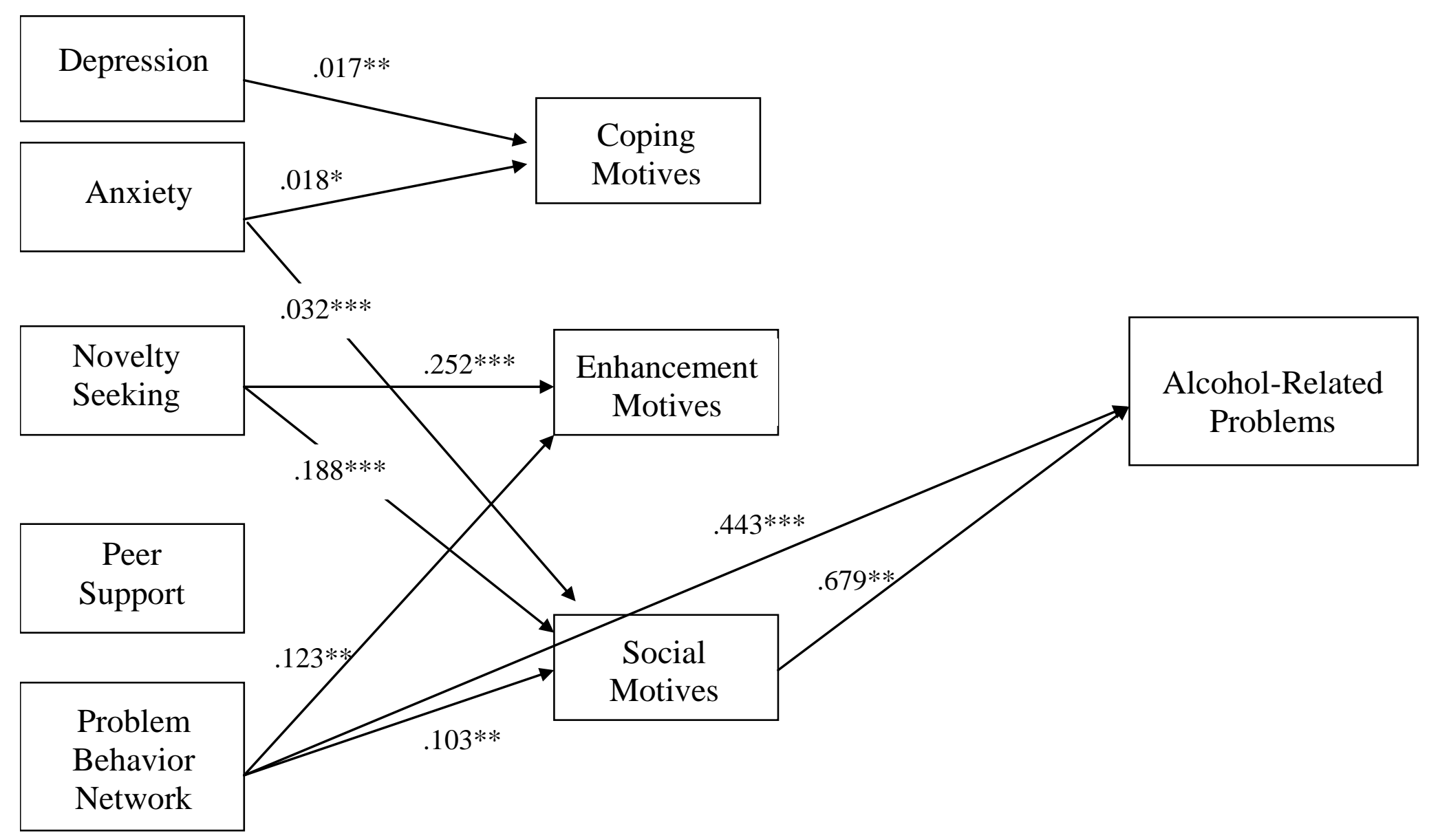

Note. Only significant structural paths are shown. $* \mathrm{p}<.05 ; * * \mathrm{p}<.01 ; * * * \mathrm{p}<.001$ for binge drinking males. Significant paths are not reported for non-binge drinking males due to the poor fit of model. 
Table 8

Longitudinal Model Fit Indices

$\chi^{2}$

Binging Females

Model 1

Model 2

$60.99 \quad 18 \quad .96$

$17.71 * \quad 13 \quad .99$

.94

.99

3.39

.10

.29

Non-Binging Females

$$
\text { Model } 1
$$

$\begin{array}{lll}55.76 & 18 & .95\end{array}$

Model 2

$19.08 * \quad 13 \quad .98$

.94

3.10

.10

.36

Binging Males

Model 1
Model 2

$36.62 \quad 18$

$18.85 * 13$

.96

.99

1.47

.05

.43

Non-Binging Males

Model 1

$\begin{array}{lll}62.99 & 18 \quad .92\end{array}$

.88

3.50

.14

.08

.26

Model 2

$21.36^{*} \quad 13$

.97

.98

1.64

.07

.30

Note: GFI = goodness-of-fit index; $\mathrm{CFI}=$ comparative fit index; RMSEA = root mean square error of approximation. ${ }^{*} \chi 2$ difference test significant at $p<.05$ between Model 1 and Model 2. 
Figure 4. Longitudinal Revised Model for Females

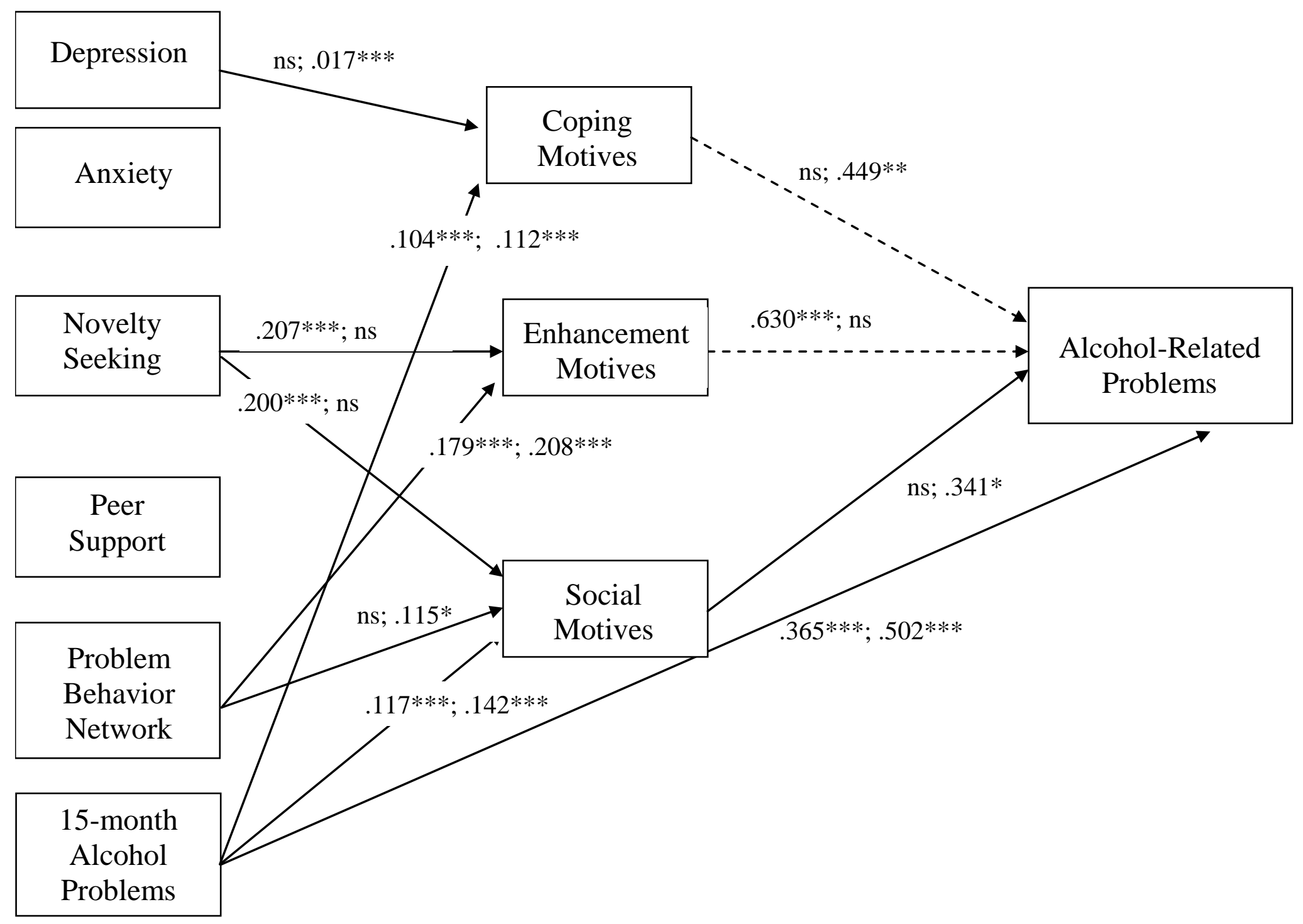


Figure 5. Longitudinal Revised Model for Males

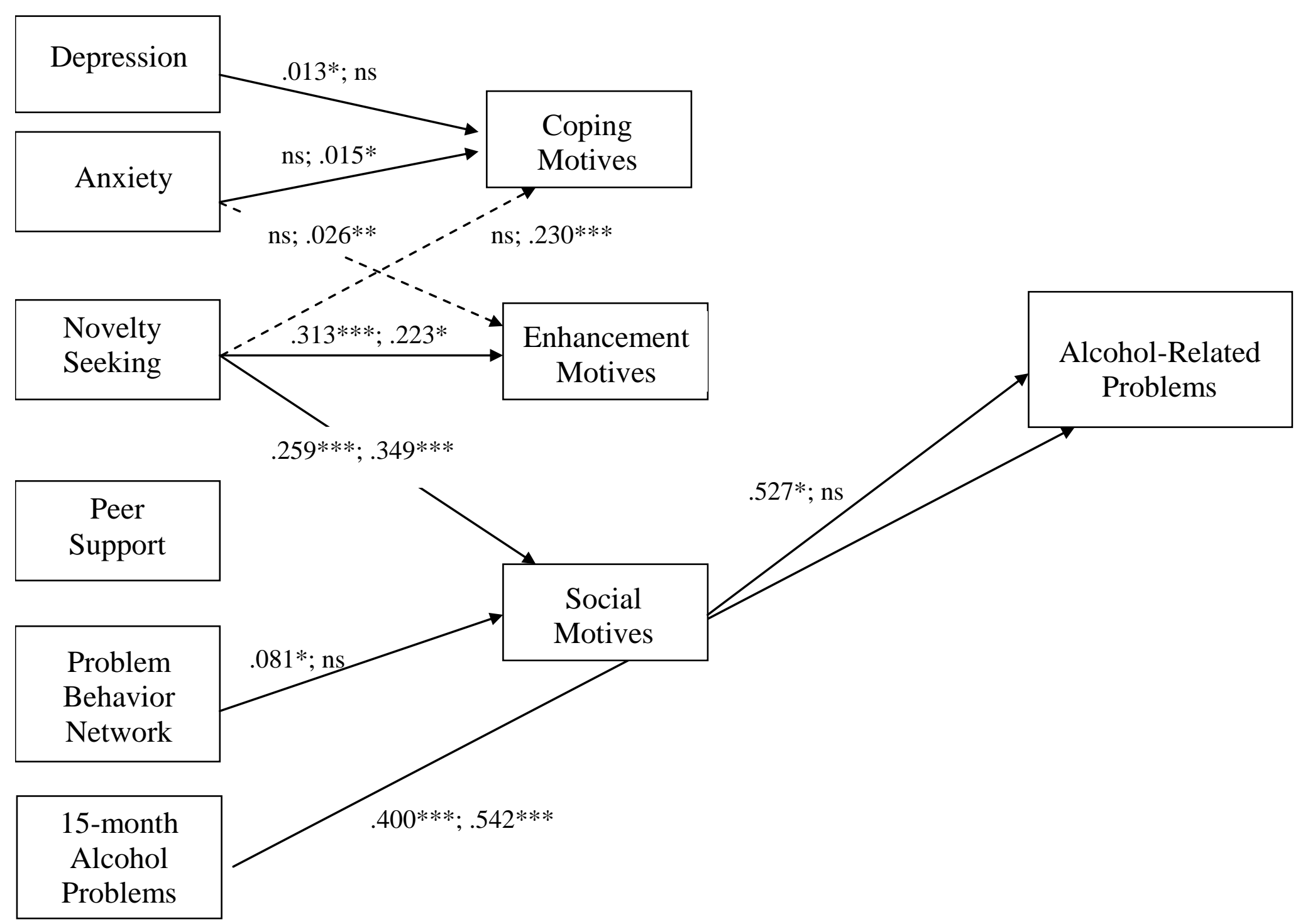


Figure 6. Female Cross-Sectional Mediated-Moderated Analyses Separated by Drinking Motives
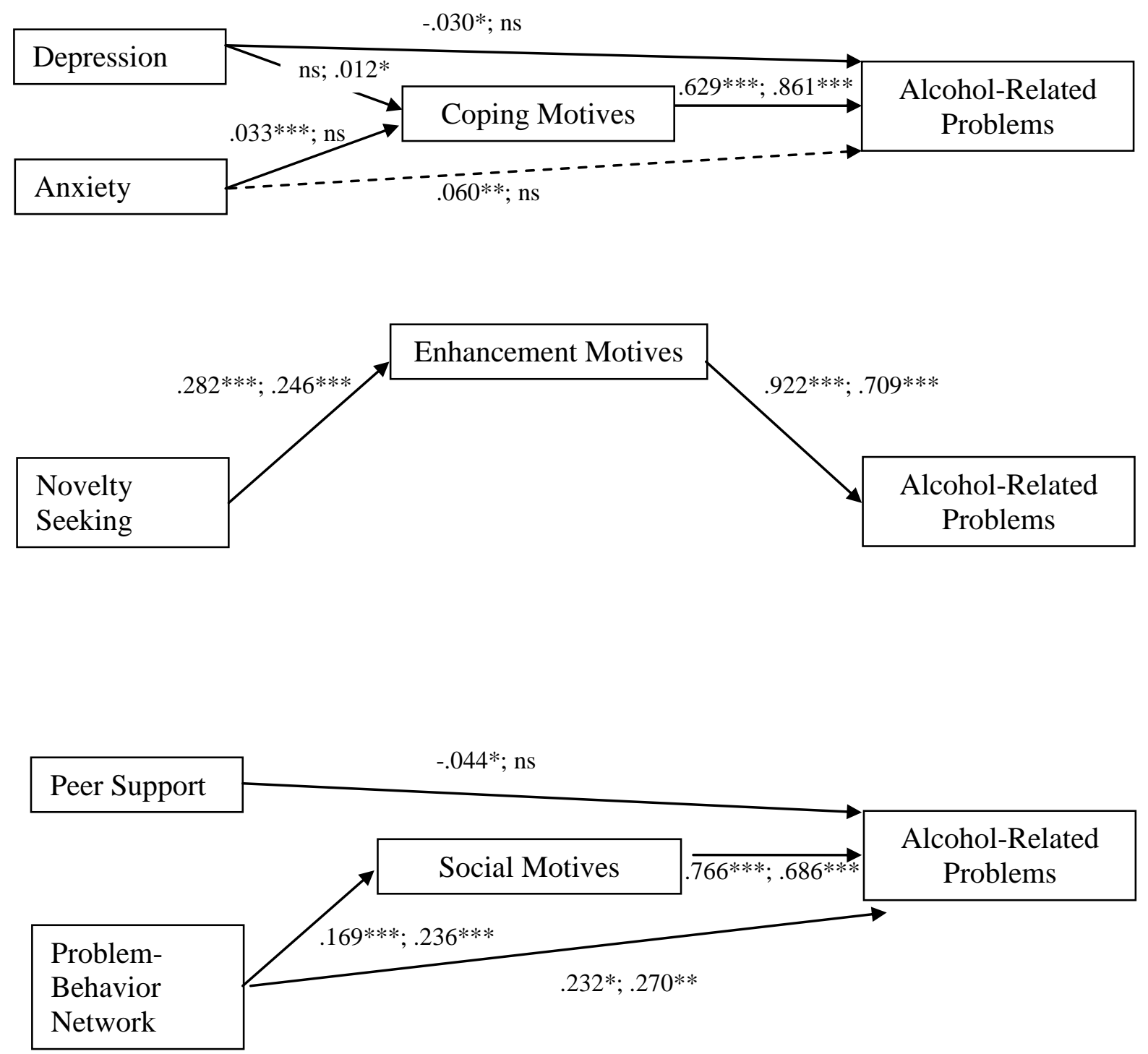

Note. Only significant paths are shown. $* \mathrm{p}<.05 ; * * \mathrm{p}<.01 ; * * * \mathrm{p}<.001$ for binge and non-binge drinking females, respectively. Dotted lines indicate those relationships that are significantly different $(\mathrm{p}<.05)$ between binge and non-binge drinkers. 
Figure 7. Male Cross-Sectional Mediated-Moderated Analyses Separated by Drinking Motives
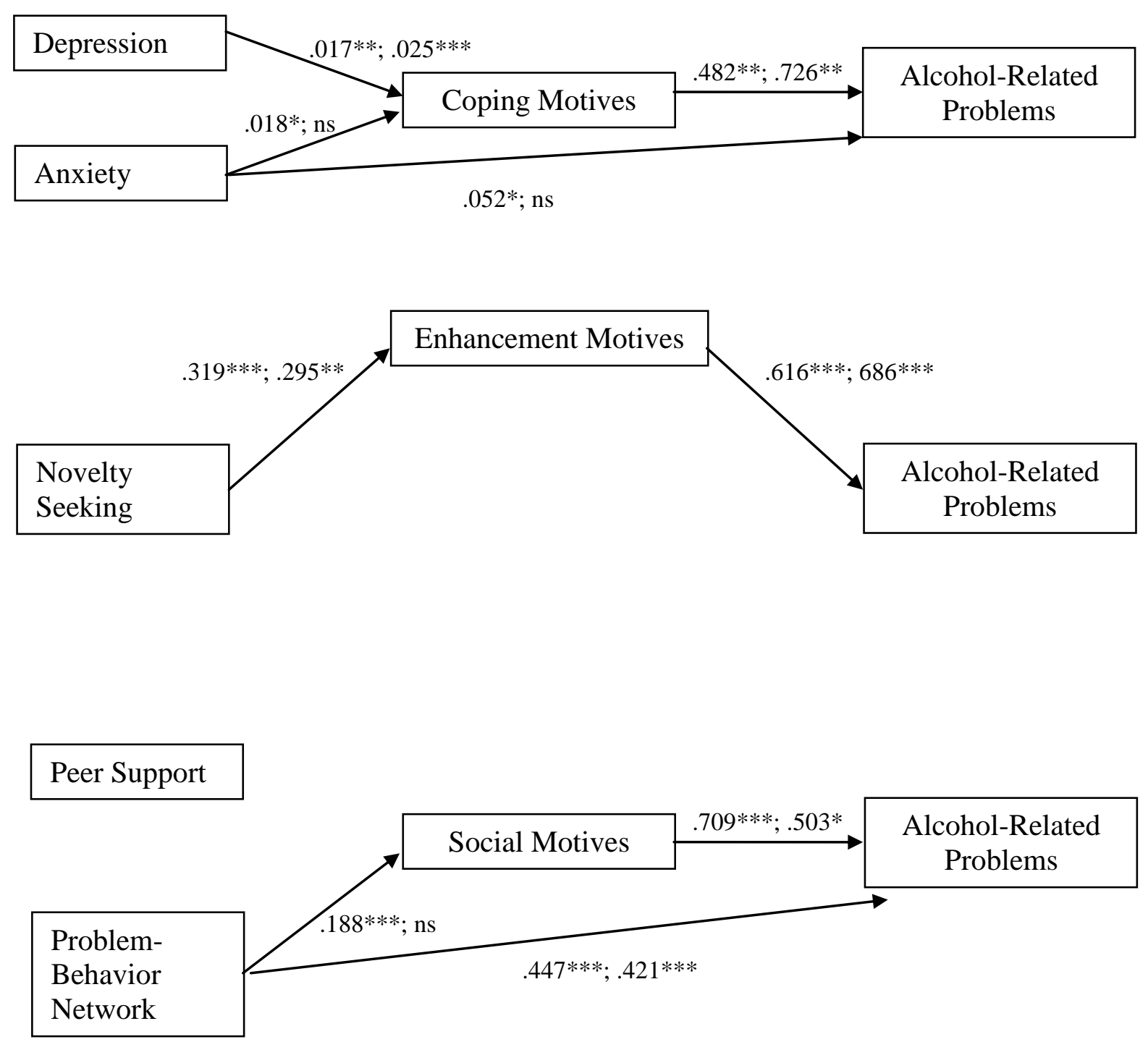

Note. Only significant paths are shown. $* \mathrm{p}<.05 ; * * \mathrm{p}<.01 ; * * * \mathrm{p}<.001$ for binge and non-binge drinking males, respectively. None of the relationships were significantly different $(\mathrm{p}<.05)$ between binge and non-binge drinkers. 
Figure 8. Female Longitudinal Mediated-Moderated Analyses Separated by Drinking Motives
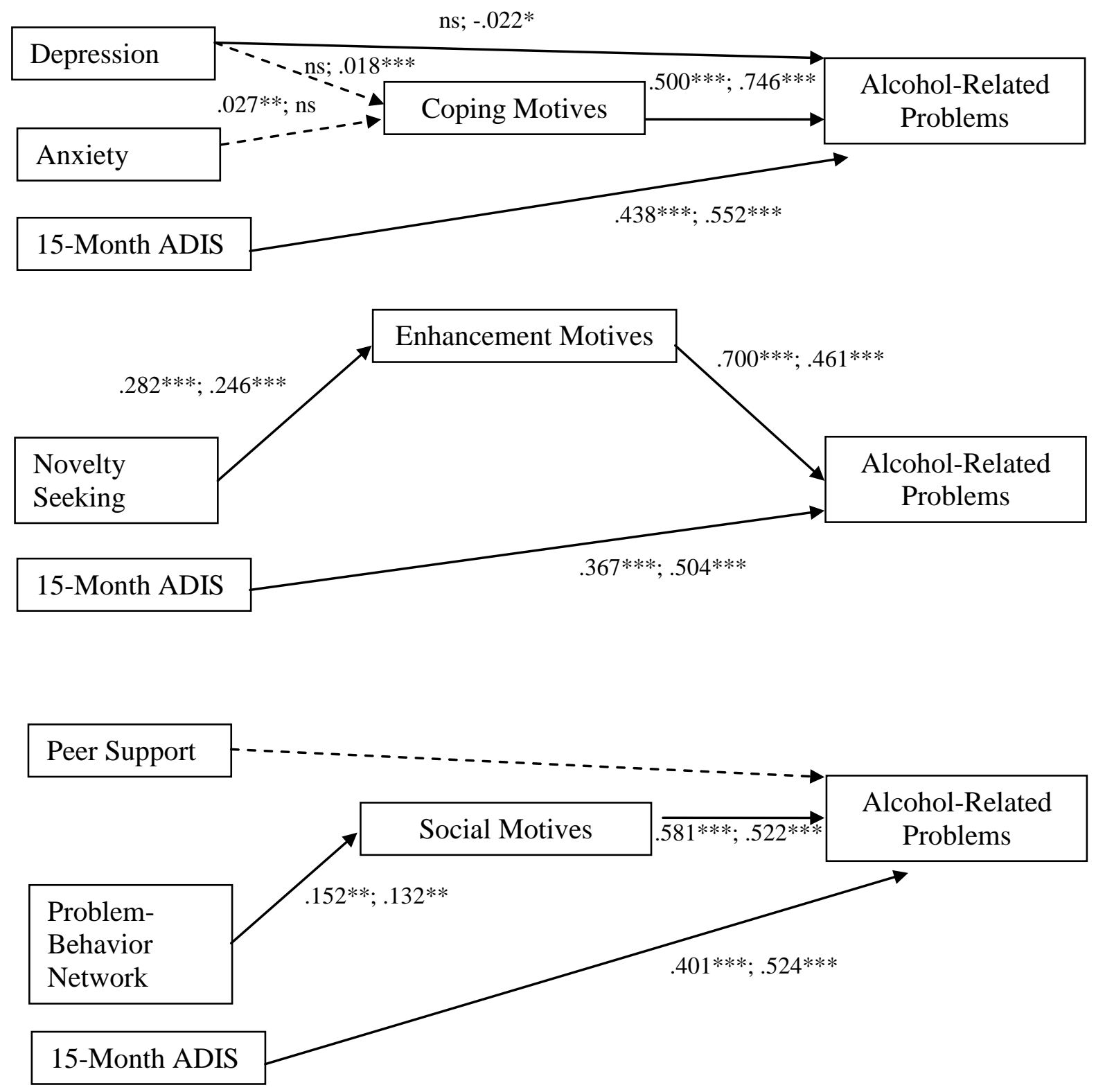

Note. Only significant paths are shown. ${ }^{*} \mathrm{p}<.05 ; * * \mathrm{p}<.01 ; * * * \mathrm{p}<.001$ for binge and non-binge drinking females, respectively. Dotted lines indicate those relationships that are significantly different $(\mathrm{p}<.05)$ between binge and non-binge drinkers. 
Figure 9. Male Longitudinal Mediated-Moderated Analyses Separated by Drinking Motives
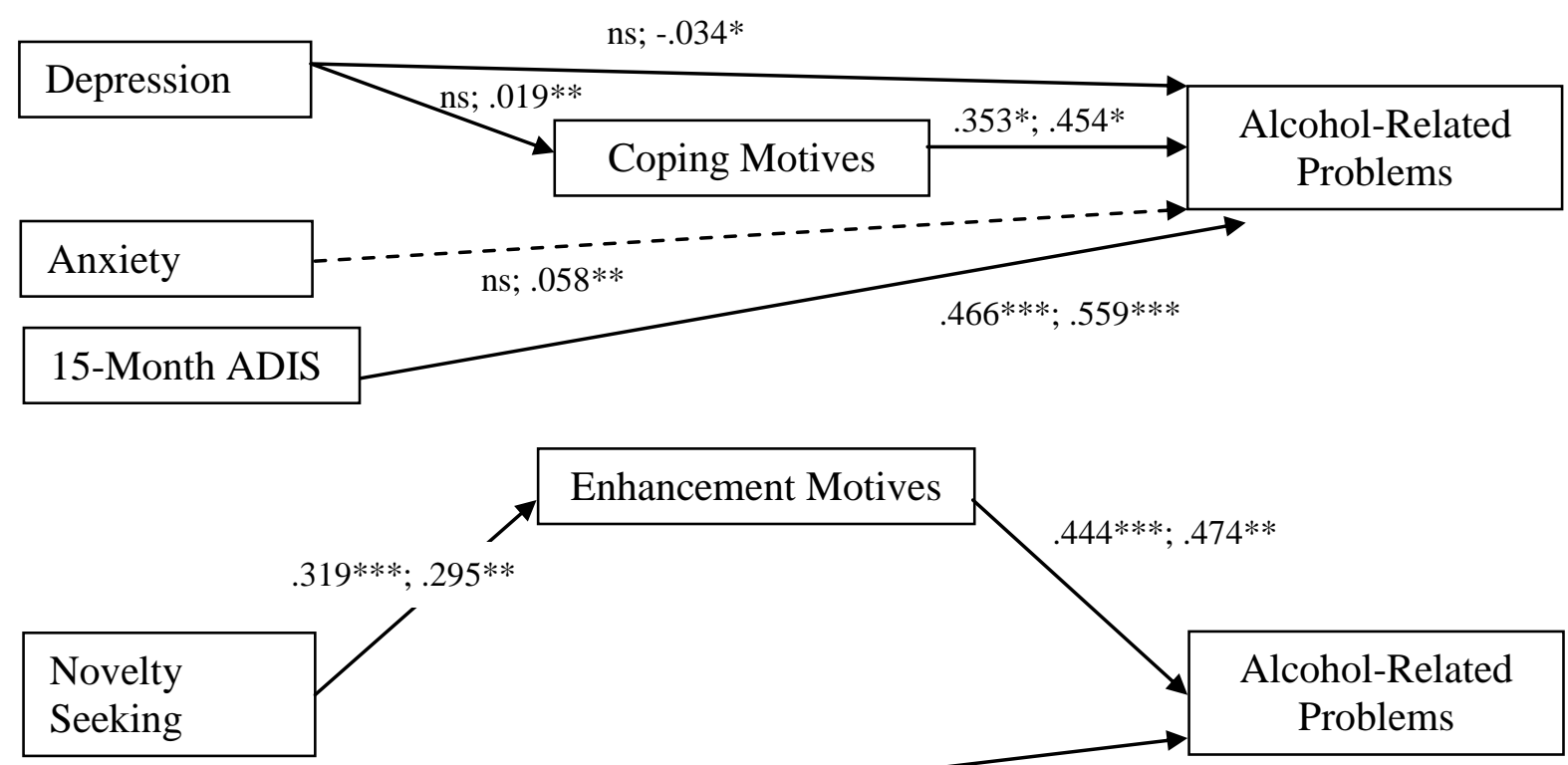

15-Month ADIS

$.432 * * * ; .547 * * *$

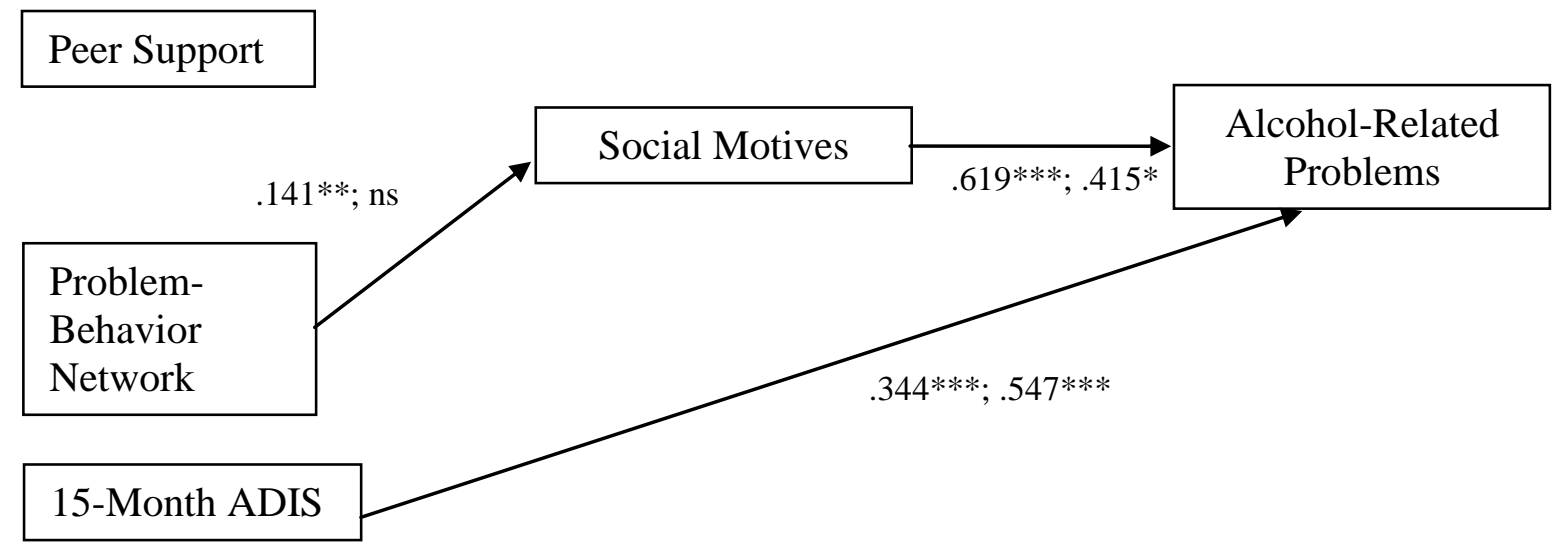

Note. Only significant paths are shown. $* \mathrm{p}<.05$; ** $\mathrm{p}<.01$; *** $\mathrm{p}<.001$ for binge and non-binge drinking males, respectively. None of the relationships were significantly different $(\mathrm{p}<.05)$ between binge and non-binge drinkers. 


\section{CITED LITERATURE}

Baker, T.B., Piper, M.E., McCarthy, D.E., Majeskie, M.R., \& Fiore, M.C. (2004). Addiction motivation reformulated: An affective processing model of negative reinforcement. Psychological Review, 111(1), 33-51.

Bonin, M.F., McCreary, D.R., \& Sadava, S.W. (2000). Problem drinking behavior in two community-based samples of adults: Influence of gender, coping, loneliness, and depression. Psychology of Addictive Behaviors, 14(2),151-161.

Bosari, B. \& Carey, K.B. (2001). Peer influences on college drinking: A review of the research. Journal of Substance Abuse, 13, 391-424.

Bradizza, C.M., Reifman, A., \& Barnes, G.M. (1999). Social and coping reasons for drinking: Predicting alcohol misuse in adolescents. Journal of Studies on Alcohol, 60, 491-499.

Brown, S.A., McGue, M., Maggs, J., Schulenberg, J., Hingson, R., Swartzwelder, S., Martin, C., Chung, T., Tapert, S.F., Sher, K., Winters, K.C., Lowman, C., \& Murphy, S. (2008). A developmental perspective on alcohol and youths 16 to 20 years of age. Pediatrics, 121, 290-310.

Chassin, L., \& DeLucia, C. (1996). Drinking during adolescence. Alcohol Health and Research World, 20(3), 175-180.

Chassin, L., Pitts, S.C., \& Prost, J. (2002). Binge drinking trajectories from adolescence to emerging adulthood in a high-risk sample: Predictors and substance abuse outcomes. Journal of Consulting and Clinical Psychology, 70(1), 67-78.

Colder, C. R., \& Chassin, L. (1999). The psychosocial characteristics of alcohol users versus problem users: Data from a study of adolescents at risk. Development and psychopathology, 11(2), 321-348. 
Collins, R.L., Koutsky, J.R., Morsheimer, E.T., \& MacLean, M.G. (2001). Binge drinking among undergraduate students: A test of a restraint-based conceptualization of risk for alcohol abuse. Psychology of Addictive Behaviors, 15(4), 333-340.

Cooney, N.L., Litt, M.D., Morse, P.A., Bauer, L.O., \& Guapp, L. (1997). Alcohol cue reactivity, negative-mood reactivity, and relapse in treated alcoholic men. Journal of Abnormal Psychology, 106(2), 243-250.

Cooper, M.L. (1994). Motivations for alcohol use among adolescents: Development and validation of a four-factor model. Psychological Assessment, 6(2), 117-128.

Cooper, M.L., Frone, M.R., Russell, M., \& Mudar, P. (1995). Drinking to regulate positive and negative emotions: A motivational model of alcohol use. Journal of Personality and Social Psychology, 69(5), 990-1005.

Cooper, M.L., Russell, M., Skinner, J.B., \& Windle, M. (1992). Development and validation of a three-dimensional measure of drinking motives. Psychological Assessment, 4(2), 123 132.

Courtney, K.E. \& Polich, J. (2009). Binge drinking in young adults: Data, definitions, and determinants. Psychological Bulletin, 135(1), 142-156.

Cox, M. \& Klinger, E. (1988). A motivational model of alcohol use. Journal of Abnormal Psychology, 97, 168-180.

Curran, P.J., Stice, E., \& Chassin, L. (1997). The relation between adolescent alcohol use and peer alcohol use: A longitudinal random coefficients model. Journal of Consulting and Clinical Psychology, 65(1), 130-140.

Deas, D. \& Thomas, S. (2002). Comorbid psychiatric factors contributing to adolescent alcohol and other drug use. Alcohol Research \& Health, 26(2), 116-121.

Deykin, E.Y., Levy, J.C., \& Wells, V. (1987). Adolescent depression, alcohol and drug abuse. American Journal of Public Health, 77, 178-182. 
Durkin, K. F., Wolfe, T. W., \& Clark, G. (1999). Social bond theory and binge drinking among college students: A multivariate analysis. College Student Journal, 33(3), 450 - 462.

Gibson, C., Schreck, C.J., \& Miller, J.M. (2004). Binge drinking and negative alcohol-related behaviors: A test of self-control theory. Journal of Criminal Justice, 32(5), 411-420.

Grzywacz, J.G. \& Almeida, D.M. (2008). Stress and binge drinking: A daily process examination of stressor pile-up and socioeconomic status in affect regulation. International Journal of Stress Management, 15(4), 364-380.

Ham, L.S. \& Hope, D.A. (2003). College students and problematic drinking: A review of the literature. Clinical Psychology Review, 23, 719-759.

Hill, K.G., White, H.R., Ick-Joong, C.J., Hawkins, D. \& Catalano, R.F. (2000). Early adult outcomes of adolescent binge drinking: Person- and variable-centered analyses of binge drinking trajectories. Alcoholism: Clinical and Experimental Research, 24(6), 892-901.

Hildebrand, K.M, Johnson, D.J., \& Bogle, K. (2001). Comparisons of patterns of alcohol use between high school and college athletes and non-athletes. College Student Journal, $35(3), 358-365$.

Hussong, A.M., \& Chassin, L. (1994). The stress-negative affect model of adolescent alcohol use: Disaggregating negative affect. Journal of Studies on Alcohol, 55, 707-718.

Hussong, A.M., Hicks, R.E., Levy, S.A., \& Curran, P.J. (2001). Specifying the relations between affect and heavy alcohol use among young adults. Journal of Abnormal Psychology, $110(3), 449-461$.

Jamison, J. \& Myers, L.B. (2008). Peer-group and price influences students drinking along with planned behavior. Alcohol \& Alcoholism, 43(4), 492-497.

Johnson, P.B., Boles, S.M., Vaughan, R., \& Kleber, H.D. (2000). The co-occurrence of smoking and binge drinking in adolescence. Addictive Behaviors, 25(5), 779-783. 
Johnston, L.D., O’Malley, P.M., Bachman, J.G., \& Schulenberg, J.E. (2013). Monitoring the Future national results on adolescent drug use: 1975-2012: Volume 1, Secondary school students. Bethesda, M.D.: National Institute on Drug Abuse.

Johnston, L.D., O’Malley, P.M., Bachman, J.G., \& Schulenberg, J.E. (2013). Monitoring the Future national results on adolescent drug use: Overview of key findings, 2012. Bethesda, M.D.: National Institute on Drug Abuse.

Johnson, K.L. \& White, K.M. (2003). Binge-Drinking: A Test of the Role of Group Norms in the Theory of Planned Behavior. Psychology \& Health, 18(1), 63-77.

Kaplow, J.B., Curran, P.J., Angold, A., \& Costello, E.J. (2001). The prospective relation between dimensions of anxiety and the initiation of adolescent alcohol use. Journal of Clinical Child Psychology, 30(3), 316-326.

Kassel, J.D., Jackson, S.I., \& Unrod, M. (2000). Generalized expectancies for negative mood regulation and problem drinking among college students. Journal of Studies on Alcohol, 61(2), 332-340.

Kassel, J.D., Weinstein, S., Skitch, S.A., Veilleux, J., \& Mermelstein, R. (2005). The development of substance abuse in adolescents: Correlates, causes, and consequences. In B.L. Hankin \& J.R.Z. Abela (Eds.), Development of Psychopathology: A Vulnerability-Stress Perspective (pp. 355-384). Thousand Oaks, CA: Sage Publications, Inc.

Keogh, E., \& Reidy, J. (2000). Exploring the factor structure of the Mood and Anxiety Symptom Questionnaire. Journal of Personality Assessment, 74, 106- 125.

Knight, J.R., Wechsler, H., Meichun, K., Seibring, M., Weitzman, E.R., \& Schuckit, M.A. (2002). Alcohol abuse and dependence among U.S. college students. Journal of Studies on Alcohol, 63, 263-270. 
Kuntsche, E., Knibbe, R., Gmel, G., \& Engels, R. (2005). Why do young people drink? A review of drinking motives. Clinical Psychology Review, 25, 841-861.

Kuntsche, E., Knibbe, R., Gmel, G., \& Engels, R. (2006). Who drinks and why? A review of socio-demographic, personality, and contextual issues behind the drinking motives in young people. Addictive Behaviors, 31, 1844-1857.

Kushner, M.G., Abrams, K., \& Borchardt, C. (2000). The relationship between anxiety disorders and alcohol use disorders: A review of major perspectives and findings. Clinical Psychology Review, 20(2), 149-171.

Larson, R. \& Richards, M.H. (1991). Daily companionship in late childhood and early adolescence: changing developmental contexts. Child Development, 62, 284-300.

Lewinsohn, P.M, Rhode, P., \& Seeley, J.R. (1998). Major depressive disorder in older adolescents: Prevalence, risk factors, and clinical implications. Clinical Psychology Review, 18(7), 765-794.

Liu, X. \& Kaplan, H.B. (1996). Gender-related differences in circumstances surrounding initiation and escalation of alcohol and other substance use/abuse. Deviant Behavior, 17(1), 71-106.

Masten, A.S., Faden, V.B., Zucker, R.A., \& Spear, L.P. (2008). Underage drinking: A developmental framework. Pediatrics, 121, 235-251.

McCabe, S.E. (2002). Gender differences in collegiate risk factors for heavy episodic drinking. Journal of Studies on Alcohol, 63, 49-56.

McCarty, C.A., Ebel, B.E., Garrison, M.M., DiGiuseppe, D.L., Christakis, D.A., \& Rivera, F.P. (2004). Continuity of binge drinking and harmful drinking from late adolescence to early adulthood. Pediatrics, 114, 714-719. 
Mermelstein, R., Cohen, S., Lichtenstein, E., Baer, J.S., \& Kamarck, T. (1986). Social support and smoking cessation and maintenance. Journal of Consulting and Clinical Psychology, 54(4), 447-453.

Miller, J.W., Naimi, T.S., Brewer, R.D., \& Everett Jones, S. (2007). Binge drinking and associated health risk behaviors among high school students. Pediatrics, 119, 76-85.

Morawska, A. \& Oei, T.P.S. (2005). Binge drinking in university students: A test of the cognitive model. Addictive Behaviors, 30(2), 203-218.

National Institute on Alcohol Abuse and Alcoholism. (2004, Winter). National Institute of Alcohol Abuse and Alcoholism Council approves definition of binge drinking. NIAAA Newsletter, 3. Retrieved May 25, 2009, from http://pubs.niaaa.nih.gov/publications/Newsletter/winter2004/Newsletter_Number3.htm

Norman, P., Bennett, P., \& Lewis, H. (1998). Understanding binge drinking among young people: An application of the Theory of Planned Behavior. Health Education Research, 13(2), 163-169.

Oei, T.P.S. \& Morawska, A. (2004). A cognitive model of binge drinking: The influence of alcohol expectancies and drinking refusal self-efficacy. Addictive Behaviors, 29, 159179.

Oetting, E.R., \& Beauvais, F. (1987). Peer cluster theory, socialization characteristics, and adolescent drug use: A path analysis. Journal of Counseling Psychology, 34, 205-213.

Pirkle, E. C., \& Richter, L. (2006). Personality, attitudinal and behavioral risk profiles of young female binge drinkers and smokers. Journal of Adolescent Health, 38(1), 44-54.

Radloff, L. S. (1977). The CES-D Scale: A self-report depression scale for research in the general population. Applied Psychological Measurement, 1(3), 385-401.

Radloff, L.S. (1991). The use of the Center for Epidemiologic Studies Depression Scale in adolescents and young adults. Journal of Youth and Adolescence, 20(2), 149-166. 
Read, J.P., Beattie, M., Chamberlain, R., \& Merrill, J. (2008) Beyond the "Binge" threshold:

Heavy drinking patterns and their association with alcohol involvement indices in college students. Addictive Behaviors, 33, 225-234.

Read, J.P., Wood, M.D., Kahler, C.W., Maddock, J.E., \& Palfai, T.P. (2003). Examining the role of drinking motives in college student alcohol use and problems. Psychology of Addictive Behaviors, 17(1), 13-23.

Reidy, J., \& Keogh, E. (1997). Testing the discriminant and convergent validity of the Mood and Anxiety Symptom Questionnaire using a British sample. Personality and Individual Differences, 23, $337-344$.

Richey, J.A., Lonigan, C.J., \& Phillips, B.M. (November, 2002). Exploratory factor analysis of the mood and anxiety symptoms questionnaire (MASQ) in a youth sample. Presented at the Annual Meeting of the Association for the Advancement of Behavior Therapy, Reno, NV.

Roberts, R.E., Andrews, J.A., Lewinsohn, P.M., \& Hops, H. (1990). Assessment of depression in adolescents using the Center for Epidemiologic Studies depression scale. Psychological Assessment, 2(2), 122-128.

Rosenberg, E.L. (1998). Levels of analysis and the organization of affect. Review of General Psychology, 2(3), 247-270.

Rutledge, P.C. \& Sher, K.J. (2001). Heavy drinking from the freshman year into early young adulthood: The role of stress, tension-reduction drinking motives, gender and personality. Journal of Studies on Alcohol, 62(4), 457-466.

Schulenberg, J., Maggs, J.L., Steinman, K.J., \& Zucker, R.A. (2001). Development matters: Taking the long view on substance abuse etiology and intervention during adolescence. In P. M. Monti, S. M. Colby, \& T. A. O’Leary (Eds.), Adolescents and substance abuse (pp. 19-57). New York: Guilford Press. 
Schulenberg, J., Wadsworth, K.N., O’Malley, P.M., Bachman, J.G., \& Johnston, L.D. (1996). Adolescent risk factors for binge drinking during transition to young adulthood: Variableand pattern-centered approaches to change. Developmental Psychology, 32(4), 659-674.

Stice, E., Barrera, M., \& Chassin, L. (1998). Prospective differential prediction of adolescent alcohol use and problem use: Examining the mechanisms of effect. Journal of Abnormal Psychology, 107(4), 616-628.

Svensson, M. (2010). Alcohol use and social interactions among adolescent in Sweden: Do peer effects exist within and/or between the majority population and immigrants? Social Science \& Medicine, 70, 1858-1864.

Terry-McElrath, Y.M., O’Malley, P.M., \& Johnston, L.D. (2009). Reasons for druge use among American youth by consumption level, gender, and race/ethnicity. Journal of Drug Issues, 39(3), 677.714.

Treiman, K.A. \& Beck, K.H. (1996). Adolescent gender differences in alcohol problem behaviors and the social contexts of drinking. Journal of School Health, 66(8), 299-304.

Tucker, J.S., Orlando, M., \& Ellickson, P.L. (2003). Patterns and correlates of binge drinking trajectories from early adolescence to young adulthood. Health Psychology, 22(1), 79-87.

Vik, P.W., Tate, S.R., \& Carrello, P. (2000). Detecting college binge drinkers using an extended time frame. Addictive Behaviors, 25(4), 607-612.

Watson, D., \& Clark, L. A. (1991). Mood and Anxiety Symptom Questionnaire. Unpublished manuscript, University of Iowa, Department of Psychology, Iowa City.

Watson, D., Weber, K., Assenheimer, J. S., Clark, L. A., Strauss, M., and McCormick R. A. (1995). Testing a tripartite model I: Discriminant validity of anxiety and depression symptom scales. Journal of Abnormal Psychology, 104, 3-14. 
Wechsler, H., Davenport, A., Dowdall, G., Moeykens, B., \& Castillo, S. (1994). Health and behavioral consequences of binge drinking in college: A national survey of students at 140 campuses. Journal of the American Medical Association, 272, 1672-1677.

Wechsler, H., Dowdall, G.W., Davenport, A., \& Castillo, S. (1995). Correlates of college student binge drinking. American Journal of Public Health, 85(7), 921-926.

Weitzman, E.R., Nelson, T.F., \& Wechsler, H. (2003). Taking up binge drinking in college: The influences of person, social group, and environment. Journal of Adolescent Health, 32, 26-35.

Wills, T.A. \& Cleary, S.D. (1996). How are social support effects mediated? A test with parental support and adolescent substance use. Journal of Personality and Social Psychology, 71(5), 937-952.

Wills, T.A., DuHamel, K., \& Vaccaro, D. (1995). Activity and mood temperament as predictors of adolescent substance use: Test of a self-regulation mediational model. Journal of Personality and Social Psychology, 68(5), 901-916.

Wills, T.A., McNamara, G., Vaccaro, D., \& Hirky, A.E. (1996). Escalated substance use: A longitudinal grouping analysis from early to middle adolescence. Journal of Abnormal Psychology, 105(2), 166-180.

Wills, T.A., Resko, J.A., Ainette, M.G., \& Mendoza, D. (2004). Role of parent support and peer support in adolescent substance use: A test of mediated effects. Psychology of Addictive Behaviors, 18(2), 122-134.

Wills, T.A., Sandy, J.M., Shinar, O., \& Yaeger, A. (1999). Contributions of positive and negative affect to adolescent substance use: Test of a bidimensional model in a longitudinal study. Psychology of Addictive Behaviors, 13(4), 327-338. 
Wills, T.A., Sandy, J.M., Yaeger, A., \& Shinar, O. (2001). Family risk factors and adolescent substance use: Moderation effects for temperament dimensions. Developmental Psychology, 37, 283-297.

Wills, T.A., \& Shiffman, S. (1985). Coping and substance use: A conceptual framework. In S. Shiffman \& T.A. Wills (Eds.), Coping and substance use (pp. 3-24). New York: Academic Press.

Wills, T.A., \& Vaughan, R. (1989). Social support and substance use in early adolescence. Journal of Behavioral Medicine, 12(4), 321-339.

Windle, M. (2003). Alcohol use among adolescents and young adults. Alcohol Research and Health, 27(1), 79-85.

Windle, M. \& Windle, R.C. (1996). Coping strategies, drinking motives, and stressful life events among middle adolescents: Associations with emotional and behavioral problems and with academic functioning. Journal of Abnormal Psychology, 105(4), 551-560.

Zuckerman, M., Kuhlman, D.M., Joireman, J., Teta, P., \& Kraft, M. (1993). A comparison of three structural models for personality: The big three, the big five, and the alternative five. Journal of Personality and Social Psychology, 65(4), 757-768. 


\section{APPENDIX A}

\section{Depressive Symptoms}

Center for Epidemiological Studies-Depression (CES-D); Radloff, 1977

Please circle the number next to each item that best reflects how often you have experienced that event in the past 7 days.

During the past week:
a. I was bothered by things that usually don't bother me.

b. I did not feel like eating; my appetite was poor...

c. I felt that I could not shake off the blues even with help from my family or friends.

d. I felt that I was just as good as other people.

e. I had trouble keeping my mind on what I was doing....

f. I felt depressed.

g. I felt that everything I did was an effort.

h. I felt hopeful about the future

i. I thought my life had been a failure

j. I felt fearful

k. My sleep was restless.

I. I was happy

m I talked less than usual

n. I felt lonely

o. People were unfriendly.

p. I enjoyed life......

q. I had crying spells

r. I felt sad......

S. I felt that people disliked me

t. I could not get going.

\begin{tabular}{|c|c|c|}
\hline None of the & Some/A & Occasionally or \\
\hline Time & Little of the & Moderate \\
\hline $\begin{array}{l}\text { (Less than } \\
1 \text { day) }\end{array}$ & $\frac{\text { Time }}{(1-2 \text { days })}$ & $\frac{\frac{\text { Amount of }}{\text { Time }}}{(3-4 \text { days })}$ \\
\hline
\end{tabular}

Most/ All of the

Time (5-7 days)

3

3

4

4

4

4

4

4

4

4

4

4

4

4

4

4

4

4

4

4

4

4 


\section{APPENDIX B}

Anxiety Symptoms

Mood and Affect Symptom Questionnaire (MASQ); Watson \& Clark, 1991; Watson, Weber, Assenheimer, Clark, Strauss, \& McCormick, 1995

Below is a list of feelings, sensations, problems, and experiences that people sometimes have. Read each statement and then mark the appropriate choice in the space next to that item. Use the choice that best describes how much you have felt or experienced things this way during the past 7 days, including today. Use the scale when answering.

\begin{tabular}{|c|c|c|c|c|}
\hline a. Felt nervous....................................... & 1 & 2 & 3 & 4 \\
\hline b. Felt faint........................................ & 1 & 2 & 3 & 4 \\
\hline c. Felt dizzy or lightheaded.................... & 1 & 2 & 3 & 4 \\
\hline 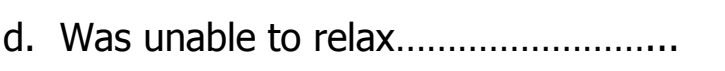 & 1 & 2 & 3 & 4 \\
\hline e. Felt like I was going crazy...................... & 1 & 2 & 3 & 4 \\
\hline f. Heart was racing or pounding............. & 1 & 2 & 3 & 4 \\
\hline g. Muscles were tense or sore.................... & 1 & 2 & 3 & 4 \\
\hline h. Worried about a lot of things............... & 1 & 2 & 3 & 4 \\
\hline
\end{tabular}




\begin{abstract}
APPENDIX C
Peer Social Support and Sense of Belonging

Will's Social Support Scale; Wills, Resko, Ainette, \& Mendoza, 2004
\end{abstract}

173. Here are some things that people may do when they

have a problem. Read each one and circle a number to

show how much you do this when you have a problem.

a. I discuss my feelings with a friend..............................

b. I get emotional support from a friend.........................

c. I get sympathy and understanding from a friend.......

d. I talk to a friend about how I feel.................................

1

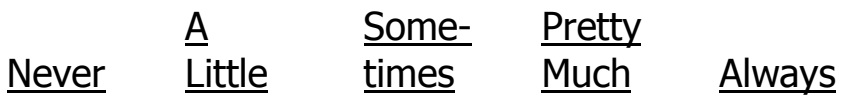

$\begin{array}{lllll}1 & 2 & 3 & 4 & 5\end{array}$

$\begin{array}{lllll}1 & 2 & 3 & 4 & 5\end{array}$

12

3

4

5

1

2

3

4

5 


\section{APPENDIX D \\ Support and Belonging to Risky Peer Networks}

Social Network Inventory for Tobacco Smokers (SNITS); Mermelstein, Cohen, Lichtenstein, Baer, \& Kamarck, 1986

For this next set of questions, think about the friends and people you go to discuss your problems, confide in, to help you to feel better, or from whom you get advice.

About how many people do you have who you could go to for these reasons?

How many of these people....

$\begin{array}{llllll}0 & 1 & 2 & 3 & 4 & 5 \text { or } \\ \text { people } & \text { person } & \text { people } & \text { people } & \text { people } & \begin{array}{l}\text { more } \\ \text { people }\end{array}\end{array}$

$\begin{array}{lllllll}\text { a. Smoke at all } & 0 & 1 & 2 & 3 & 4 & 5+ \\ \begin{array}{l}\text { b. Never drink alcohol } \\ \begin{array}{l}\text { c. Drink alcohol less than once } \\ \text { a week }\end{array}\end{array} & 0 & 1 & 2 & 3 & 4 & 5+ \\ \end{array}$

d. Drink alcohol at least once a week

0

1

2

3

4

$5+$

e. Get in trouble at school or work every once in a while

$\begin{array}{llllll}0 & 1 & 2 & 3 & 4 & 5+\end{array}$

f. Frequently get in trouble at school or work

g. Usually get good grades in school 


\section{APPENDIX D (continued)}

Now think about the friends and people you usually hang out with or do things with (like go to the movies with, go places with, have over to your house, etc.).

About how many people do you have who fit this description?

How many of these people....

$\begin{array}{llllll}0 & 1 & 2 & 3 & 4 & 5 \text { or } \\ \text { people } & \text { person } & \text { people } & \text { people } & \text { people } & \begin{array}{l}\text { more } \\ \text { people }\end{array}\end{array}$

$\begin{array}{lllllll}\text { a. Smoke at all } & 0 & 1 & 2 & 3 & 4 & 5+\end{array}$

b. Never drink alcohol

0

c. Drink alcohol less than once a week

0

d. Drink alcohol at least once a week

0

1

2

3

4

$5+$

e. Get in trouble at school or work every once in a while

0

1

2

3

4

$5+$

f. Frequently get in trouble at school or work

1

2

3

4

$5+$

g. Usually get good grades in school

0

1

2

3

4

$5+$ 


\section{APPENDIX E}

Drinking Motives

Drinking Motives Scale; Cooper, Russell, Skinner, \& Windle, 1992

The following questions ask you about various reasons why you may drink alcohol. Please choose the most appropriate answer from the following response options.

I drink...

a. As a way to celebrate.

b. To relax

c. Because I like the feeling.....

d. Because it is what most of my friends do when we get together......

e. To forget my worries

f. To get high.

g. To be sociable

h. Because it helps when I feel depressed or nervous

i. Because it's fun.

j. Because it is customary on special occasions.

k. To cheer up when I'm in a bad mood..

I. Because it's exciting

$\mathrm{m}$. Because it makes a social gathering more enjoyable.

n. Because I feel more self-confident or sure of myself..

o. Because it makes me feel good...

\section{Almost never/Never} Sometimes Frequently

Almost

Always

4

4

1

1

1

1

1

1

1

1

1

1

1

1

1
2

3

2

2

2

2

2

2

2

2

2

2

2

3

3

3

3
4

4

4

4

4

4

4

4

4

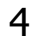

4

4

4 
APPENDIX F

Alcohol Use: Past Three Months Use and Alcohol Problem Scale

DURING THE PAST 3 MONTHS HOW OFTEN DID YOU...

\begin{tabular}{llll} 
& $\begin{array}{l}\text { More than } \\
\text { once a month } \\
\text { but less than } \\
\text { once a week }\end{array}$ & $\begin{array}{l}\text { One or more } \\
\text { times a week } \\
\text { Once a month not } \\
\text { times }^{1}\end{array}$ overy day $^{4}$ & Every day $^{5}$ \\
\hline
\end{tabular}
a. Have at least one
drink of alcohol
b. Smoke marijuana
c. Use cocaine
d. Use any amphetamines

e. Use hallucinogenic drugs

f. Sniff inhalants

g. Take any drugs with a needle

h. Use steroids

i. Use prescription medications not meant for you 


\section{APPENDIX F (continued)}

When did you last drink alcohol?

(1) I have never drank alcohol

(5) Several weeks ago

(2) Over a year ago

(3) 6-12 months ago

(6) Last week or a few days ago

(4) A few months ago

(7) Yesterday

(8) Today

When you drink alcohol, how much do you usually have at one time, ON AVERAGE?
(1) I don't drink alcohol
(2) 1 drink or less
(3) 2 drinks
(4) 3 drinks

(6)

(5) 4 drinks

5 drinks

(7) 6 drinks

(8) more than 6 drinks

What is the greatest amount of alcohol you've ever had at one time?
(1) I don't drink alcohol
(2) 1 drink or less
(6)
(5) 4 drinks
(3) 2 drinks
5 drinks
(4) 3 drinks
(7) 6 drinks
(8) more than 6 drinks

During the past year, how often have you gotten drunk?
(1) 0 times
(2) 1 to 2 times
(3) 3 to 4 times
(4) 5 to 10 times
(5) more than 10 times

During the past year, how often have you gotten into trouble because of drinking alcohol?
(1) 0 times
(2) 1 to 2 times
(3) 3 to 4 times
(4) 5 to 10 times
(5) more than 10 times 


\begin{tabular}{|c|c|c|}
\hline \multicolumn{3}{|l|}{ APPENDIX G } \\
\hline \multicolumn{3}{|l|}{ Alcohol-Related Problems } \\
\hline \multicolumn{3}{|c|}{ Adolescent Alcohol- \& Drug-Related Problems Scale (ADIS); Colder \& Chassin, 1999} \\
\hline \multicolumn{3}{|c|}{$\begin{array}{l}\text { Please indicate whether the following events have happened to you in the past } 6 \text { months as a } \\
\text { result of drinking alcohol or using drugs by circling Yes or No. }\end{array}$} \\
\hline \multicolumn{3}{|l|}{ Have you (as a result of drinking alcohol or using drugs)... } \\
\hline $\begin{array}{l}\text { Had a problem with, or complaints from, your } \\
\text { family or friends? }\end{array}$ & (1) Yes & (2) No \\
\hline $\begin{array}{l}\text { Been in trouble at school or work (for example, missing school } \\
\text { or losing a job)? }\end{array}$ & (1) Yes & (2) No \\
\hline Been in trouble with the police? & (1) Yes & (2) No \\
\hline Had an accident or injury? & (1) Yes & (2) No \\
\hline $\begin{array}{l}\text { Awakened the morning after and found that you couldn't } \\
\text { remember things that had happened the night before? }\end{array}$ & (1) Yes & (2) No \\
\hline $\begin{array}{l}\text { Ended up drinking/using more than you had expected to when } \\
\text { you began? }\end{array}$ & (1) Yes & (2) No \\
\hline
\end{tabular}




\title{
CATHERINE M. YORK, Ph.D.
}

\author{
Clement J. Zablocki VA Medical Center \\ $5000 \mathrm{~W}$. National Ave. \\ Milwaukee, WI 53295 \\ (414) 384-2000 (ext. 41178) \\ catherine.york2@va.gov
}

EDUCATION

2013 - Present

Neuropsychology Post-Doctoral Fellow

Clement Zablocki VA Medical Center, Milwaukee

$2012-2013$

Psychology Intern

VA Ann Arbor Medical Center

$2007-2013$

Ph.D., Clinical Psychology

University of Illinois at Chicago

2005-2007

M.A., Clinical Psychology

University of Illinois at Chicago

2001- 2005

\author{
B.A., Cum Laude and University Honors in \\ Applied Psychology \\ Minor in History \\ University of Illinois at Chicago
}

\section{THESES}

Daily mood and alcohol use among adolescents. Master of Arts in Psychology. University of Illinois at Chicago, 2007. Committee: Robin J. Mermelstein (Chair), Jon D. Kassel, Katie Witkiewitz.

Exploring the differences in drinking motives among adolescent binge and non-binge drinkers. Doctor of Philosophy in Psychology. Committee: Robin J. Mermelstein (Chair), Jon D. Kassel, Audrey Ruderman, Larry Grimm, Colleen Corte.

\section{PROFESSIONAL CLINICAL EXPERIENCE}

$8 / 2013$ - Present

Neuropsychology Post-Doctoral Fellow

Clement Zablocki VA Medical Center

Current duties include conducting neuropsychological and psychodiagnostic assessments on outpatients and inpatients. I am also involved in the Polytrauma and Parkinson's Disease Clinics, which includes conducting interviews and brief cognitive screens. I also supervise a neuropsychology practicum student.

Supervisors: Thomas Hammeke, Ph.D., ABPP-CN, Eric Larson, Ph.D., ABPP-CN, and Kathleen Patterson, Ph.D. 
Completed an inpatient neuropsychology/geropsychology rotation and an outpatient neuropsychology rotation. My main duties included supervising several undergraduate research assistants conducting neuropsychological screens and conducting full neuropsychological assessments. My minor rotations were in the Substance Use Disorders Clinic and Compensation and Pension.

Major Supervisors: Kenneth Adams, Ph.D., ABPP-CN, Linas Bieliauskas, Ph.D., ABPP-CN, Henry Buchtel, Ph.D

Minor Supervisors: Steven Chermack, Ph.D. and Steven Putnam, Ph.D.

$5 / 2011-7 / 2012$

\section{Neuropsychometrist}

Carle Foundation Hospital, Urbana, IL

Worked as a neuropsychometrist (40 hours/week). My main duties included neuropsychological assessment and scoring for adolescent and adult patients.

Supervisor: Douglas E Grant, Ph.D.

$1 / 2010-5 / 2011$

\section{Practicum Student}

Neuropsychology

VA Illiana Healthcare System, Danville, IL

Worked with adult neuropsychological patients. Primary work included clinical interviews, neuropsychological assessment and scoring, and report writing. I also assisted in conducting Compensation and Pension evaluations.

Supervisor: Julie Fitzgerald-Smith, Ph.D.

$8 / 2010-5 / 2011$

\section{Practicum Student}

Substance Abuse Rehabilitation Program

VA Illiana Healthcare System

Worked with substance dependent adults. Primary work included initial assessment/diagnostic interviews, individual therapy, leading and co-leading various treatment groups using Rational Emotive Therapy, case management, and participation in biweekly staff meetings. I also developed and co-led a Tobacco Cessation group, as well as developed scoring programs for commonly used measures using Excel.

Supervisor: Jeffrey DeBord, Ph.D. 
$10 / 2010-12 / 2010$

Practicum Student

Primary Care Mental Health

VA Illiana Healthcare System

Spent ten weeks in Inpatient Psychiatry in which the focus was to gain exposure to the severely mentally ill as well as to learn how to complete intakes and assessments with that population as they present for inpatient hospitalization. I also participated in treatment team meetings.

Supervisor: Mark Blodgett, Psy.D.

$7 / 2008-6 / 2009$

\author{
Neuropsychology Extern \\ Neuropsychology Institute \\ University of Illinois Medical Center
}

Worked as a part of a team with adult neuropsychological patients. Primary work included full neuropsychological assessments and report writing. I also participated in weekly group supervision and didactics (e.g., neuroanatomy series and neuropsychology rounds).

Supervisors: Neil H. Pliskin, Ph.D., ABPP-CN \& David L. Nyenhuis, Ph.D., ABPP-CN

$9 / 2005-5 / 2009$

Student Clinician

Office of Applied Psychological Services

UIC Psychology Department

Primary work included intake interviews, psychodiagnostic assessments, and individual psychotherapy. Worked with both children and adults.

Supervisors: Gloria Balague, Ph.D., Nancy Dassoff, Ph.D., \& Audrey Ruderman, Ph.D.

$5 / 2007-6 / 2008$

Practicum Student

Adolescent Obesity Clinic

UIC Nutrition and Wellness Center

Worked as a part of a multidisciplinary team with a pediatrician, a dietician, medical residents, and medical students. Primary work included general psychosocial assessments and motivational interviewing.

Supervisors: Kathy Diviak, Ph.D. \& Christine Stahl, M.D.

$1 / 2005-5 / 2005$

Child Life Services Intern

Rush University Medical Center, Chicago

Provided care and activities for hospitalized infants, children, and their families. Researched and developed a protocol on the use of toys as "healing mechanisms" to aid hospitalized children, their families, and other Child Life staff in the child's developmental and emotional well-being. 
Supervisor: Kathryn Engel, M.S.

RESEARCH EXPERIENCE

$8 / 2005-8 / 2008$

Graduate Research Assistant

Institute for Health and Research Policy

University of Illinois at Chicago

Assistant to Dr. Robin Mermelstein on a project entitled "The Social-Emotional Contexts of Adolescent Smoking”. Duties included assisting in management of IRB protocols, managing and analyzing large statistical data sets, managing large mailings and recruitment efforts, and revising and updating research protocols.

$9 / 2003-5 / 2005$

\author{
Undergraduate Research Assistant \\ Department of Psychology \\ University of Illinois at Chicago
}

Assistant to Dr. Jon D. Kassel conducting research in the area of tobacco and alcohol use. Duties included assisting in recruitment, conducting Structured Clinical Interviews for the DSM-IV-R, and assisting in the management and entering of data for a large alcohol and tobacco use study. Also assisted in the recruitment and administration for a study of Negative Mood Regulation Expectancies in undergraduate college students, as well as assisting graduate students with independent projects.

\title{
PUBLICATIONS
}

Veilleux, J.C., Colvin, P.J., Anderson, J., York, C., \& Heinz, A.J. (2009). A review of opioid dependence treatment: Pharmacological and psychosocial interventions to treat opioid addiction. Clinical Psychology Review, 30, 155-66.

Perry, S., York, C., Bottoms, B., Block, S., Goodman, G. (2009). Child Witnesses. In Jamieson, A. \& Moenssens, A. (Eds.) Encyclopedia of Forensic Science.

\section{PUBLICATIONS IN PREPARATION}

York, C. \& Mermelstein, R. (in preparation). The Objective and Subjective Context of Adolescent Drinking Episodes.

\section{PROFESSIONAL CONFERENCE PRESENTATIONS}

York, C.M., Gable, N.M., Boxley, L.R., \& Bieliauskas, L.A. (2013, June). Exploring the Relationship between Self-Reported Alcohol Use and Effort on a Neuropsychological Screen in a Veteran Outpatient TBI Clinic. Poster presented at the Annual Conference for the American Academy of Clinical Neuropsychology, Chicago, IL.

York, C.M. \& Mermelstein, R.J. (2008, November). The Impact of Peer Support on the Relationship between Stress and Alcohol Use among Adolescents: Does It Matter Whom You Turn to for Support? Poster presented at the Annual Conference for the Association for Behavioral and Cognitive Therapies, Orlando, FL. 
Shartzer, C.M. \& Mermelstein, R.J. (2007, May). Daily Mood and Solitary Alcohol Use among Adolescents. Poster presented at the Annual Conference for the Association of Psychological Science, Washington, D.C.

Shartzer, C.M. \& Mermelstein, R.J. (2007, March). Objective and Subjective Mood Contexts for "Real-Time" Drinking Episodes among Adolescents. Poster presented at the Annual Conference for the Society of Behavioral Medicine, Washington, D.C.

Shartzer, C.M., Evatt, D., Yates, M., \& Kassel, J.D. (2005, May). Problem Drinking Behavior Among Binge Drinkers: The Role of Drinking Motives. Poster presented at the Annual Conference of the Midwestern Psychological Association, Chicago, IL.

\section{TEACHING EXPERIENCE}

Co-Instructor (VA Ann Arbor Medical Center)

Weekly Didactic Lectures for Undergraduate Research Assistants

Instructor (University of Illinois at Chicago)

Abnormal Psychology (Spring 2008)

Teaching Assistant (University of Illinois at Chicago)

Abnormal Psychology (Fall 2008; Fall 2009 - present)

Psychological Interventions (Spring 2009)

Psychology of Interviewing (Fall 2008; Spring 2009)

Statistical Methods in Behavioral Science (Fall 2007)

Introductory Psychology (Fall 2005; Spring 2006)

\section{Guest Lectures (VA Ann Arbor Medical Center)}

Psychiatry Grand Rounds (November 2012)

Topic: Longitudinal Effects of Mild Traumatic Brain Injury and Post-Traumatic

Stress Disorder Comorbidity on Postdeployment Outcomes in National Guard

Soldiers Deployed to Iraq

\section{Guest Lectures (University of Illinois at Chicago)}

Neuropsychology Group Supervision (May 2009)

Topic: Normal Pressure Hydrocephalus vs. Schizophrenia

Abnormal Psychology (June 2008)

Topic: Stress, Psychological Factors, \& Health

Psychology and the Law Brown Bag (April 2008)

Topic: Treatment for Sexual Offenders

Abnormal Psychology (October 2007)

Topic: Eating Disorders

Psychology and the Law Brown Bag (April 2007)

Topic: Solitary Alcohol Use in Adolescence: A Trajectory of Poor Outcomes?

Clinical Psychology Brown Bag (March 2007)

Topic: Daily Mood and Alcohol Use among Adolescents

Psychology and the Law Brown Bag (October 2006)

Topic: Are Psychopaths in a Class of Their Own? 
Neuroanatomy and Neuroimaging for Psychologists (2012; sponsored by the University of Michigan)

Clinical Neuroanatomy Course (2011; sponsored by the National Academy of Neuropsychology DistanCE).

Wechsler Adult Intelligence Scale - Fourth Edition (2008; sponsored by the UIC Office of Applied Psychological Services).

Introduction to Mixed Models for Longitudinal Continuous Data (2008). Presented by Don Hedeker, Ph.D. (sponsored by the Association for Psychological Science).

Psychology and Law Coursework (2006-2008). Specialized courses included Psychology \& Law; Children, Law, \& Psychology; and five semesters in Current Topics in Psychology and Law)

The Ethical Principles and Code of Conduct for Psychologists: Clinical, Assessment, and Forensic Issues (2006). Presented by Neil H. Pliskin, Ph.D. (sponsored by the Association for Behavioral and Cognitive Therapies).

NEPSY - Second Edition (2005; sponsored by the UIC Office of Applied Psychological Services).

ACADEMIC HONORS AND AWARDS

2007 University of Illinois at Chicago Graduate Student Council/Graduate College Recipient of a Travel Award to the Society of Behavioral Medicine Annual Conference, Washington D.C., March 2007

2007 Society of Behavioral Medicine Recipient of a Meritorious Student Poster Award

2001-2005 UIC Honor's College - Member

2001-2005 UIC College of Liberal Arts \& Sciences Undergraduate Dean's List Qualified for the Dean's List five semesters.

2005 University of Illinois, Chicago - Chancellor's Student Service Award This award "honors students who have made an outstanding contribution to the University through campus and community service".

2005 University of Illinois Alumni Association - Activities Honorary Society This award "recognizes and honors undergraduate students who have made an impact on the UIC community by participating in diverse student organizations". 

Scholarship

Recipient of scholarship awarded to a UIC undergraduate who is the child of Vietnam veteran. $(\$ 600)$

2003 General Assembly Community Service Scholarship Recipient of academic scholarship for students in Representative David E. Miller's district who pursue a baccalaureate at one of the Illinois state universities (covered three semesters of tuition)

Walmart/Sam's Club Foundation Scholarship (\$1000)

\title{
PROFESSIONAL SERVICE
}

$2002-2009$

\author{
Board Member and Alumni Volunteer \\ Liberal Arts and Sciences \\ Alumni Association
}

Served as the Undergraduate Student Representative from 2002-2005. Served as the Secretary of the board and as the chair of the Scholarships and Awards Committee from 2006-2009.

$2005-2009$

\author{
Alumni Volunteer \\ University of Illinois Alumni Association
}

Served on various committees in relation to student activities, including the Activity Honorary Society selection committee. I also remained active with students in the Student Alumni League by volunteering at their annual events.

$2003-2005 \& 2008-2009$

\author{
Board Member \\ UIC College Alumni Advisory Committee
}

Served as the Undergraduate Student Representative from 2003 - 2005 and then as the Liberal Arts and Sciences Alumni Board Representative from 2008 - 2009.

Fall 2008

Assistant to the Coordinator

Office of Applied Psychological Services

Assisted the Directors of Clinical Training and the Coordinator of OAPS with the APAaccreditation review and visit. Also assisted coordinator with daily tasks, as well as taking inventory and organizing all assessment materials. 
Honorary:

Psi Chi: National Honor Society of Psychology

Phi Beta Sigma National Honor Society

Phi Kappa Phi National Honor Society

National Society of Collegiate Scholars

Professional:

American Psychological Association

APA Division of Neuropsychology (40)

Association for Psychological Science

International Neuropsychological Society

National Academy of Neuropsychology 